\title{
New Zealand Early Childhood Pre-service Teachers' Perceptions of Practicum and Potential for Video Review.
}

by

Susie Bassett

A thesis submitted to Victoria University of Wellington in partial fulfilment of the requirements for the degree of Master of Education

Victoria University of Wellington

$31^{\text {st }}$ July 2019 


\begin{abstract}
This qualitative study of 20 pre-service early childhood teachers investigated the students' perceptions of their practicum experiences and views of the potential for video review use using two on-line surveys of Student Teachers (STs) in their second and third year of study in a New Zealand undergraduate three-year degree Initial Teacher Education Programme (ITEP). This study found STs perceived practicum as highly significant within their ITEP and value practicum opportunities to develop their knowledge and skills in the real-world context of ECE centres with children and within teaching teams. However, STs reported a wide range of perceived challenges indicating that the practicum is problematic at times. These challenges involve the establishment of relationships and communication, transparency of assessment practices, and STs' agency. These issues appear interrelated and impact upon student teacher responses within, and perceptions of, their practicum experience. Students were ambivalent to the potential use of video review while also recognising the benefits to their teacher development. The findings of this study provide further evidence of the need to re-examine the traditional practicum model and to consider alternative approaches by ITEP's including video review.
\end{abstract}




\section{Acknowledgments}

My Supervisor, Sue Cherrington, provided the spaces for essential dialoguing and patiently attended to endless drafts. I am extremely grateful for Sue's support and expert guidance throughout this study.

Thank you to the students that took the time to contribute their experiences. I'm very grateful for your assistance in generating this work. I hope I have been able to capture a little of your experiences for further discussion.

I am enormously thankful for the Golden Bay community - nudging me forward as I worked through this study and forever encouraging me with persistent inquiries over the sounds of the coffee grinder and heat from the ovens.

My family's patience and love has been extraordinary. John and Tom, thank you for accepting the long silences, occasional outbursts and mumblings while reading aloud to myself.

Thank you too to my parents, Marie and lan. I'm proud of what I carry of you both. 


\section{Table of Contents}

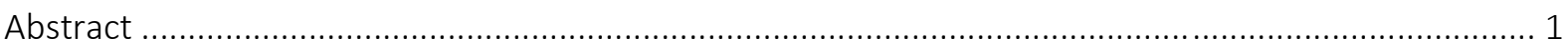

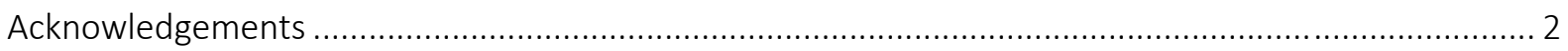

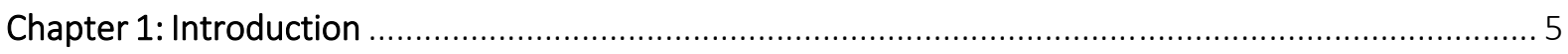

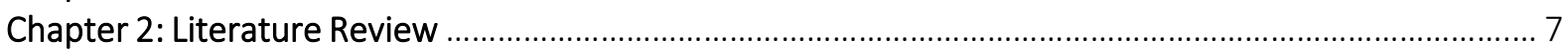

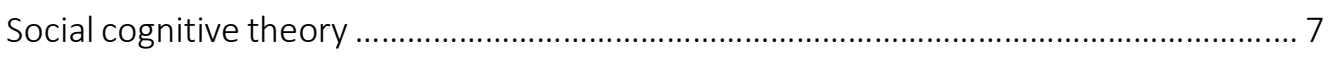

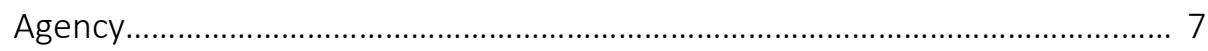

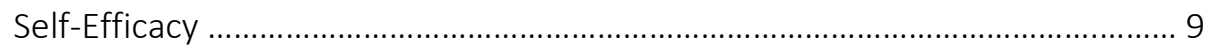

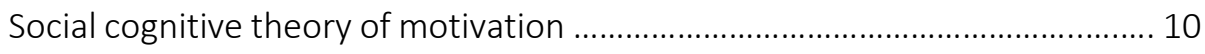

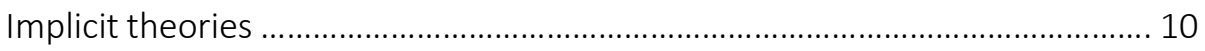

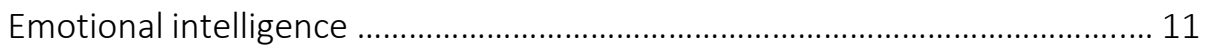

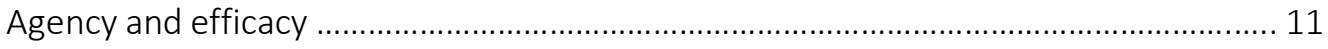

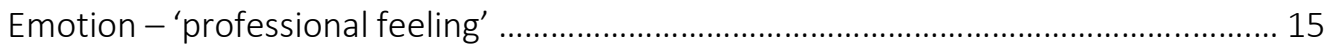

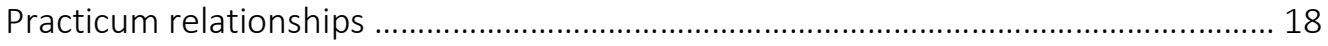

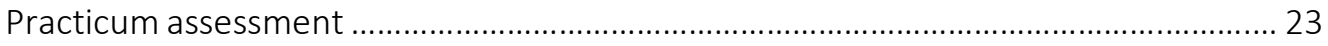

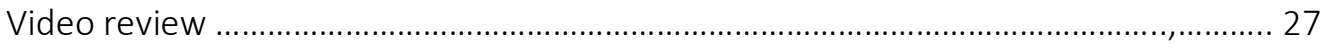

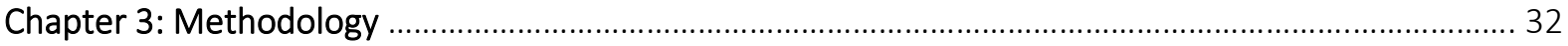

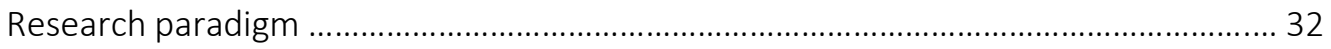

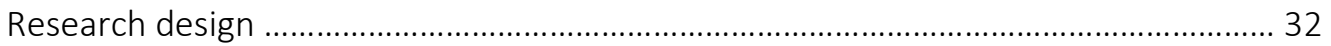

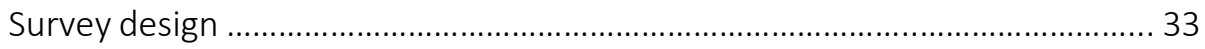

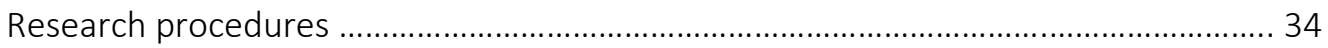

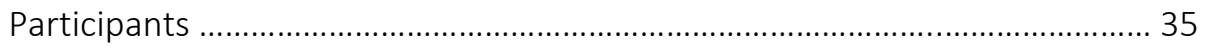

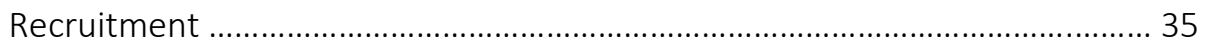

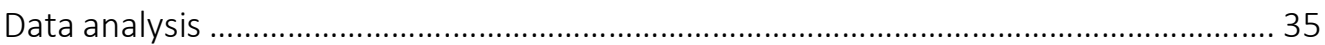

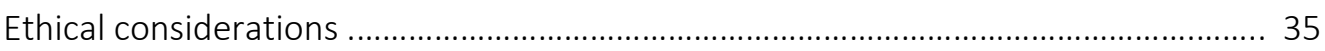

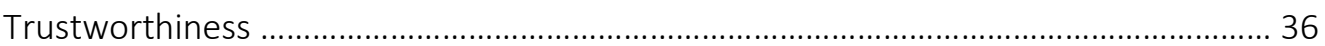

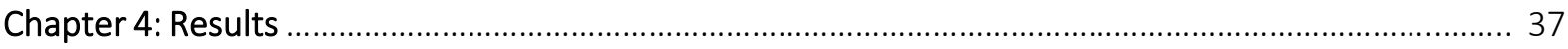

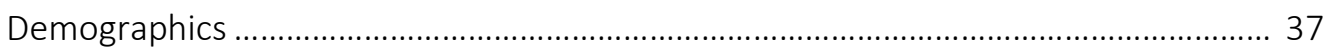

Significance of practicum, goals and challenges ..................................................... 38

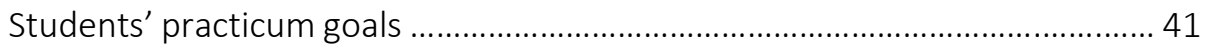

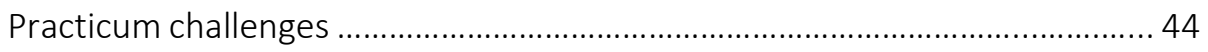

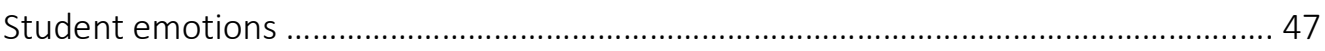

Perceived source of feelings ....................................................................... 51

Associate teacher and visiting lecturer assessment .................................................... 52

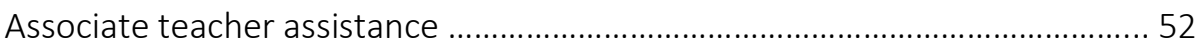

Associate teacher feedback ......................................................................... 55

Associate teacher communication and relationship ....................................... 56

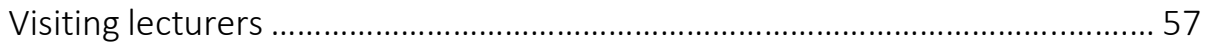

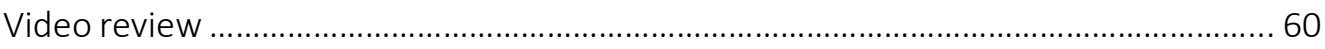

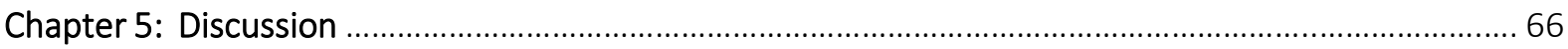

Developing practical skills and confidence: emotion and agency .............................. 66

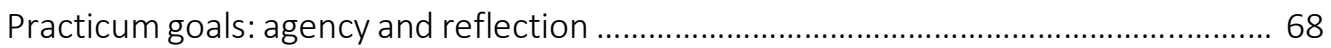

Relationships and assessment: transparency and agency ............................................ 70

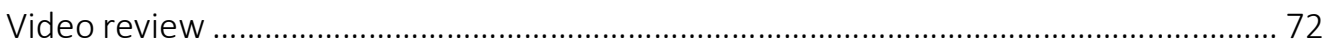

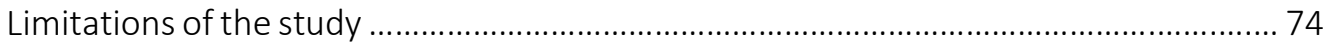

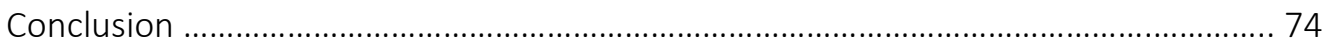

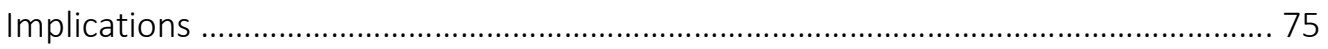

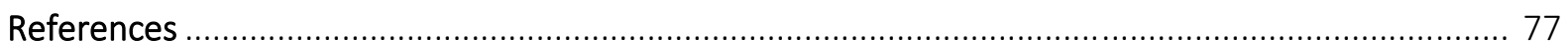

Appendix A: Recruitment invitation and participant information email Survey questions ..................... 81

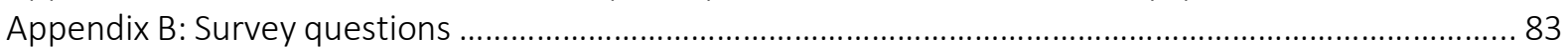




\section{List of Tables}

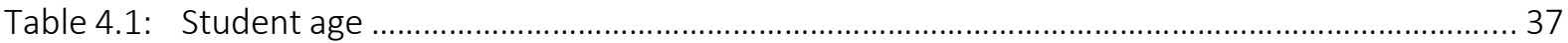

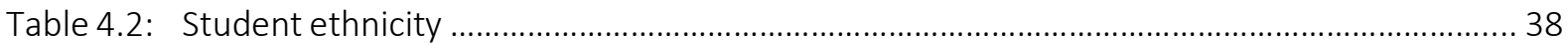

Table 4.3: Aspects of practicum: student teachers' perception of significance to their teacher

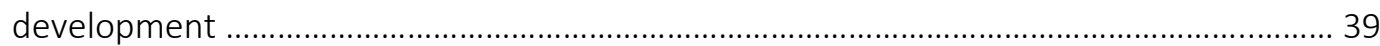

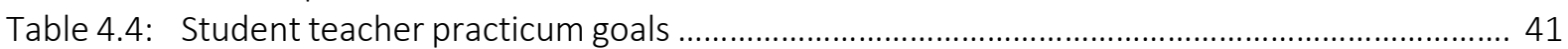

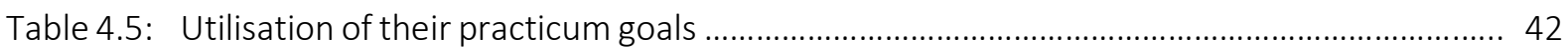

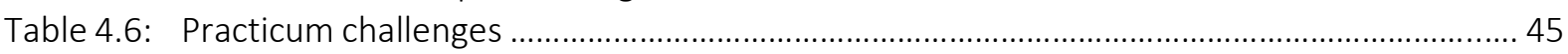

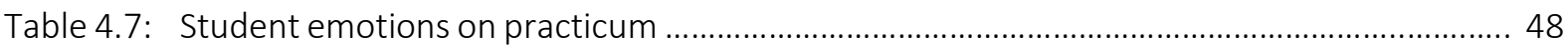

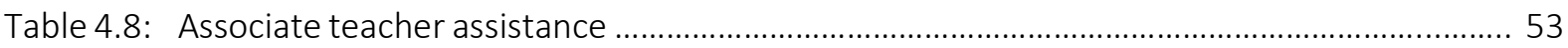

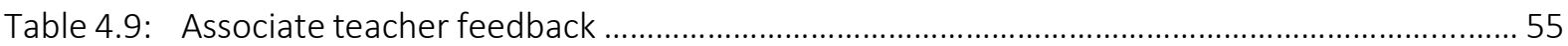

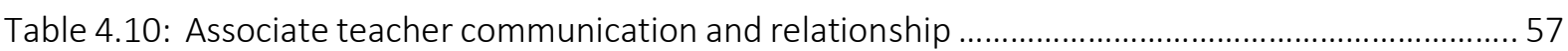

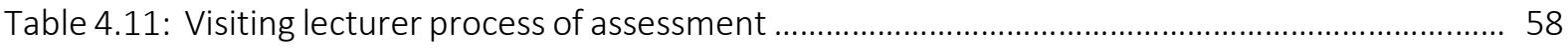

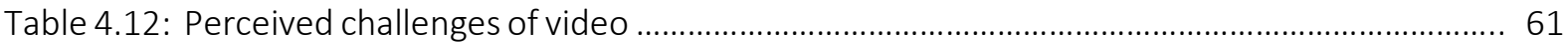

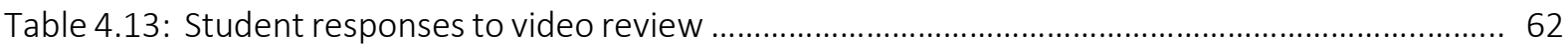

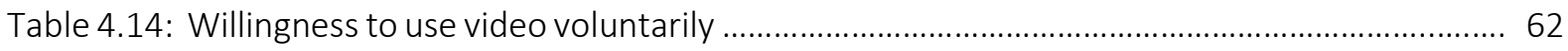




\section{Chapter one: Introduction}

This study arose from the experiences of the researcher with Student Teachers (STs) on practicum, her own reflective practice as both an early childhood teacher, teacher trainer, through her postgraduate studies, and involvement in teacher appraisals utilising Video Review (VR). That practicum experience is an integral aspect of initial teacher education (ITE) appears uncontested although debate of the 'theory-practice' divide of ITE remains contentious as increasing demands are placed upon ITE's to provide teaching ready candidates in Early Childhood Education (ECE) centres and schools. While extensive research has been undertaken internationally to better understand how the practicum functions within student teacher development and ITE programmes, teacher practicum models appear to have remained largely unchanged with the key practicum triad members, the student teacher, Associate teacher (AT) and Visiting lecturer (VL) central in the practicum assessment model continuing to be used in much the same ways in New Zealand (NZ).

ECE in NZ is diverse in provision for children under the age of 5 years. In NZ teachers work in teams of three or more, often in open settings where children of mixed ages attend together. Children may be attending full-day, half day or school day services and educators are involved in both care and education of children in indoor/outdoor settings. These factors pose challenges in drawing insights from international research studies where educators may be working alone in classrooms reviewing practices from a lesson-based model of teach, test and review unfamiliar in the NZ ECE context.

STs' in ECE ITE programmes have practicum experiences as a core component of their preparation as a teacher each year. Placed in ECE centres working with children from infants to five-year-old children, STs are supervised by an AT who provides advice and guidance and a VL. Associate teachers are qualified teachers who mentor and supervise student teachers, and may or may not have a leadership role within the ECE centre STs are placed in. VLs are employed by the ITE programme, either as faculty members or as contract staff and may or not be familiar with the ST.

Both the AT and VL are the assessors of the STs' competence during practicums, although ultimately it is the ITE programme that will sign off that the graduating Student Teacher meets the Education Council's Graduating Teacher Standards. Visiting lecturers' assessment of students are usually undertaken over a period of two to two and a half hours. VLs observe student practice working with children for a minimum of one hour, with the remaining one to one and a half hours generally consisting of professional discussion with the student and the AT. A written report summarising the observation, discussion and recommendations are provided to the student. ATs provide ongoing formative feedback throughout the practicum and a final summative assessment report at the conclusion of the placement. 
The assessment of the practical component of the practicum (teaching criteria) are linked closely to New Zealand Education Council's (NZEC) Graduating Teacher Standards (2005). Tertiary institutions vary in the timing, content and assessment of teaching practicum although the NZEC's programme approval of ITE programmes stipulates a minimum quantity of professional practice depending on the length of the programme. A shift in NZEC's (2019) policy expands the ATs' responsibility to mentor and assess the ST to include the whole ECE centre team. Another NZEC change in emphasis has been to require VLs to be members of ITE faculty. Through my experiences as a VL assessing STs during practicum, questions have continued to surface for me about how STs perceived their ITE programme's preparation for practicum, their experiences within practicum and the roles of visiting lecturers (VL) and associate teachers (AT) in both supporting and enhancing their teacher development. My anecdotal experiences within the traditional practicum assessment model of observation and discussion with STs and ATs indicated that some STs may not be clear about what they wanted to develop, how to work toward this or measure their progress and how ATs viewed their relationship within the practicum model. My postgraduate study and exploration in the use of VR in teacher appraisal gave rise to my interest in further investigating STs' perceptions of their experiences and their views about video review use during practicum.

This chapter has outlined the rationale for the study and the current Education Council requirements for the practicum component of ITE programmes. Chapter two presents a review of relevant literature whilst Chapter three outlines the research design and methodological decisions made for this study. The results are presented in Chapter four before the thesis concludes with a discussion of the study's findings, limitations and implications for future research. 


\section{Chapter 2: Literature review}

For the purposes of this literature review I have focussed primarily on research investigating student teacher perceptions of their practicum experience and, in particular, foregrounding relevant NZ ECE research. However, where there were gaps in either the preservice teacher education or NZ literature I have supplemented this literature with relevant research undertaken with practising teachers.

The review has been grouped into six sections. It begins with a discussion of the theoretical constructs underpinning the study; followed by examination of empirical literature into student teachers' or teachers' agency and efficacy and emotions together with studies that have addressed the areas of relationships, assessment, and video review within the practicum. Many of the empirical studies while primarily described in one section are also relevant to other sections and so may be discussed more than once.

\section{Social cognitive theory}

The underlying theoretical construct of this study has its origins in Bandura's Social-cognitive theory, the emphasis of which is understanding social behaviour. Social cognitive theory has been applied in the fields of education, psychology, and health. Social cognitive theory seeks to explain why and how people choose to act as they do. Bandura's central premise is that learning occurs in a social context through observation. Further, the factors of environment, thought, personality and behaviour act in a reciprocal manner to influence learning in self-directed goal-oriented ways. Thus, the outcomes one anticipates also influence future actions, motivation and behaviour in a cyclical responsive manner. Bandura views humans as active agents who both are influenced by and influence their social and learning environment. Bandura's concept of personal agency explains one's adaptability, reflexivity and capacity to act intentionally whilst his concept of efficacy explains one's motivation. High and low motivation relate to high and low achievement, so beliefs about ability appear integrally related. Dweck and Leggett (1988) and Dweck (2000) proposed that motivation and learning response are strongly associated with implicit theories. This seems particularly relevant to teaching and learning as motivation and achievement appear strongly related, reciprocally influential and malleable.

\section{Agency}

Agency encompasses a person's ability to make choices and act upon these to affect their world, thus people influence their own behaviour as well as the environment in a goal directed manner. In social cognitive theory, agency is an action rather than a capacity, competence or quality that one has (Goddard, Hoy \& Woolfolk Hoy, 2000). It is, then, what one does intentionally within a specific situation (Biesta, Priestley \& Robinson, 2015) and is contingent on perceived challenge (Goddard et 
al., 2000). Bandura does not preclude relational goals, social purposes nor emotion in knowledge construction and behaviour; rather he acknowledges that affective experience and knowledge is inherent within agency. Personal agency and social systems are interdependent and influence each other. It is not then, the individual acting in self-interest within the social world but the social world influencing the experiences, goals and choices of people. For instance, Bandura suggests "that a high sense of efficacy promotes a prosocial orientation characterised by cooperativeness, helpfulness, and sharing with a vested interest in each other's welfare" (Bandura, 2001. p. 15). Four factors are exercised to affect one's choice of action - intentionality; forethought; self-reactiveness; and selfreflectiveness (Bandura, 2001) - which may also be thought of as planning, anticipating, motivating and evaluating/monitoring.

Intentions are choices one makes about what one hopes to bring about and require plans of action. As such, they are a future focused commitment to action requiring forethought and engage selfregulatory orientations such as motivation. Forethought requires anticipation and selection of actions likely to produce desired outcomes and which influence whether one discards those that may be detrimental. Forethought motivates and guides one's actions and priorities. Bandura noted that choices people make to produce the outcomes they desire are complex and neither solely externally driven or intrinsically motivated.

Self-reactiveness (or self-directed self-regulation) links thought to action helping to motivate and determine courses of action. This involves self-monitoring as one compares performance with goals and personal standards. Goals need to be challenging to activate strong interest, investment and engagement. "General goals are too indefinite and noncommitting to serve as guides or incentives" (Bandura, 2001, p.8) and need to combine short term incremental goals within a broad long-term aspiration to be powerfully motivating. Goals adopted without having a way of measuring progress may not assist motivation. Self-reflectiveness is viewed by Bandura as a metacognitive activity through which one judges outcomes and the effect of one's actions. Efficacy, the belief in one's ability to exercise some measure of control over self and environmental events is central, without which there is little incentive to make meaning from experience. Central to this concept is how the social selfreactive mind interprets experience to create self-theories which then influence the construction of one's beliefs about the value of our own actions and motivates behaviour.

Bandura distinguished between three modes of human agency: personal (individual), proxy (enlisting other's assistance to act on one's behalf to effect) and collective (group). Bandura asserted people do not seek or desire universal control over all aspects of their lives because it would be impossible to know, consider and master the skills required. Mastery, he maintained, is gained only over time with 
effort, responsibility and risk. Bandura suggested that people are not always eager to shoulder these responsibilities and so surrender control to others in activities which they are still able to influence, hence, proxy agency. A key ingredient of collective agency is a shared belief in the collective influence of a group to produce desired results. This concept is relevant to ECE settings where teachers work in a team in close proximity to one another in a collaborative manner. Goddard, Hoy and Woolfolk Hoy (2000) developed this further in their conceptualisation of collective efficacy to effectively examine the efficacy beliefs of schools and the resulting impact on student achievement.

\section{Self-efficacy}

Self-efficacy has a central role in human agency as it relates to the belief in one's ability to create a specific outcome, thus is a judgement of ability, is task specific and future oriented. "Efficacy beliefs play a central role in the self-regulation of motivation through goal challenges and outcome expectations" (Bandura, 2001, p.10). Efficacy is developed through experience and observation. Efficacy beliefs influence the outcomes one anticipates, future actions, motivation and goal setting. Thus, people's choices about which challenges to undertake, how much effort to expend, how long to persevere in the face of difficulty and whether failures are motivating or demoralising (Goddard et al., 2000) are influenced by their efficacy beliefs.

The development of efficacy is influenced by: mastery experiences; vicarious experiences; verbal persuasion; and physiological and emotional states (Goddard et al., 2000).

- Mastery experiences are the strongest influences on efficacy as experiencing a string of successes promotes a reasonable expectation that one can succeed in the task again. However, it needs to be a demanding task that strengthens persistence in the face of challenges.

- Vicarious experiences need to be modelled by those who are perceived to have a similar degree of experience to evoke a sense of trust in the model and one's belief in their ability to emulate their practice.

- Verbal persuasion includes encouragement and feedback from those one respects and trusts. It can influence effort and support persistence in the face of setbacks which may lead to increased problem solving and innovation. Perceived failure, however, can also undermine confidence in the sources of feedback (Dweck, 2000). Feedback and encouragement have the powerful potential to both build or undermine efficacy. Dweck (2000) found praising ability inadvertently undermined agency and efficacy, while reinforcing effort and the strategies utilised by learners motivates more adaptive beliefs and learning behaviours. 
- Physiological and affective states have a powerful influence in the interpretation of one's performance and subsequent efficacy. As cues to underlying beliefs and thoughts, selfawareness and a capacity to both interpret and re-interpret information about one's ability are required. Several studies have highlighted emotional and physiological stress and the ability to stay unaffected by negative beliefs about success (Goddard et al., 2000; Fives, Hamman, \& Olivarez, 2007).

Bandura maintained efficacy beliefs influence the types of activities and environments people choose to engage in. These choices promote the development of competencies, values and interests particular to those social settings and environments. "Thus, by choosing and shaping environments people have a hand in what they become" (Bandura, 2001, p.11). The concepts of agency, efficacy, motivation, learning disposition and goals are further addressed by Dweck and her research (1988, 2000) and are explored in the next section.

\section{Social cognitive theory of motivation}

Dweck and Leggett's (1988) exploration of possible sources of learning motivation in learning contexts posed the notion of implicit theories of intelligence. They maintained that people largely have either an entity theory of intelligence or an incremental theory of intelligence. These theories, they assert, orient people to choose different achievement goals (performance or learning), influence learning responses to challenges (helpless or mastery dispositions) and subsequent perceptions and persistence. An entity theory of intelligence is one that perceives intelligence as fixed and unable to be changed. An Incremental theory of intelligence perceives intelligence to be malleable and so able to be cultivated with effort and guidance. A performance achievement goal is one that is extrinsically motivated whilst a learning achievement goal is intrinsically motivated.

\section{Implicit theories}

Implicit theories of intelligence were defined by Dweck (2000) as a person's beliefs about their own (and other's) intelligence and whether they can alter their achievement through motivation to be successful. Implicit theories are not based on the reality of one's skills but on perceptions and beliefs.

Dweck (2000) proposed that our reactions to approval and challenge lie at the heart of motivation and subsequent vulnerability and resilience. These intersect with Bandura's assertion of belief-based efficacy. Dweck suggests those holding an entity theory are oriented to performance achievement goals and when confronted with challenges are likely to respond in a 'helpless' manner, increasing vulnerability. Those with an incremental theory are oriented to learning achievement goals and when confronted with challenge are likely to respond with a 'mastery' disposition and an increase of effort, hence building persistence and resilience. 
According to Dweck, implicit theories are developed in response to experience, beginning in early childhood with parental and teacher judgements expressed through praise and criticism in response to children's learning behaviours. Dweck also suggested that implicit theories influence effort, perceptions of challenge, responses to obstacles or setbacks and beliefs about one's own and others ability and personality, both in the present and future. This may have significant implications for STs in their work with children as their own implicit theories are likely to be reinforced in their interactions with young children.

\section{Emotional Intelligence}

The work of Goleman (1996) on emotional intelligence (EI) places the recognition and regulation of affective states at the core of human functioning. El can be defined as the ability to recognise, interpret and respond effectively to emotion both within oneself and in others. Key personal traits articulated in this theory include: self-awareness or the capacity to monitor and to accurately identify one's own emotions, and which is evidenced by confidence and self-deprecating humour; selfregulation is the skills to manage disruptive emotions and impulses and adapt to changing situations, and is evidenced by openness, integrity and trustworthiness; intrinsic motivation involves the disposition to be driven to pursue goals with optimism, effort and curiosity with less regard for other's approval or reward; empathy which is the capacity to recognise and understand how others feel; and the social skills required to initiate, build and sustain relationships.

Goleman saw emotional intelligence as playing a dual role to both assist recognition (self-awareness and social-awareness) and aid regulation (self-management and relationship/social management). Goleman maintained that such skills are able to be grown and adapted, thus remain malleable throughout one's life experience.

Teaching practicum and the first years of teaching have the most powerful influence on self-efficacy which over time appears to stay relatively stable and difficult to change (Tschannen-Moran \& Woolfolk Hoy, 2001). Dweck found that implicit theories were also malleable. The roles of affective states in learning appear to be closely tied to cognition and motivation. Many existing studies into the practicum and student teachers' experience of the practicum have drawn upon these theoretical frameworks and the next section of the chapter reviews some of these empirical studies with a particular focus on efficacy and agency.

\section{Efficacy and Agency}

Goddard, Hoy and Woolfolk Hoy (2000) suggest that while agency may be thought of as one's "intentional pursuit of a course of action" (p. 483), individual efficacy involves believing in one's own ability to carry out specific tasks. More specifically, teacher-efficacy refers to a teacher's judgement 
about their ability to effectively influence desirable student learning. Studies have found teacherefficacy influences teacher performance, both individually and collectively. The specificity of teacherefficacy beliefs and teaching behaviour appears routinely measured in relation to teachers' use of instructional strategies, classroom management and student engagement (Tschannen-Moran \& Woolfolk Hoy, 2001). The concept of teacher-efficacy has been extended to the examination of the collective efficacy of teachers' shared beliefs within whole schools to increase student achievement (Goddard et al., 2000).

Teacher-efficacy has been variously defined as "a teacher's personal assessment and beliefs about their capacity to accomplish teacher related outcomes and the influence they feel that they have on children's learning and development" (Van Schagen Johnson, La Paro \& Crosby, 2017, p.231) and "teachers' beliefs in their abilities to organise and execute courses of action necessary to bring about desired results" (Fives et al., 2007, p.917). The remaining studies reviewed in this section have investigated the development of agency in STs (Turnbull, 2005) and teachers (Biesta, et al., 2015; Gibbons, Tesar, Steiner \& Chan, 2018); relationships between teacher-efficacy and practicum satisfaction, feelings and 'fit' (Van Schagen Johnson et al., 2017); support and symptoms of burnout (Fives et al., 2007); and experience and personality traits (Bullock, Coplan \& Bosacki, 2015).

Turnbull's (2005) case study explored the development of six NZ ECE STs' professional agency during their final practicum. Turnbull's initial definition of professional agency was ambitious. Turnbull refined her definition for further research as "the capacity of the student teacher (or other professional educator) to effectively apply appropriate knowledge, skills, understandings and dispositions in professional practice contexts" (2005, p. 207).

Turnbull found four interacting practicum factors that either enabled or hindered STs' professional agency: the practicum learning environment (team relational climate, degree of collaboration and acknowledgement); ST professional knowledge (ST confidence in pedagogical and philosophy of practice); professional relationships and communication skills (collaborative, addressed conflict and tension); ST professional dispositions (demonstrated consistent professional behaviours). While Turnbull found STs agentic in relation to transforming practicum experiences with which they were confronted (such as tensions, alternate views and competing priorities), only half of the STs achieved professional agency as first defined above. Turnbull (2005) suggested that ITE programmes could better prepare STs and ATs for practicum by encouraging ST self-awareness (professional behaviours) and communication skills that might be utilised to manage the more challenging aspects of practicum relationships. 
Van Schagen Johnson et al. (2017) surveyed 32 ECE STs' early practicum experiences. They investigated socio-emotional aspects of ST experience (such as ST reports of their feelings in the practicum setting and their perceived ' $f$ it' with the AT), overall practicum satisfaction, and teacherefficacy. They found ST satisfaction to be the biggest predictor of teacher efficacy, ahead of feelings and 'fit'. However, the socio-emotional aspects of feelings and 'fit' did influence both efficacy and satisfaction, indicating the inter-related nature of these factors. They suggest that satisfaction was a compilation of STs' practicum experiences (including feelings, fit and unmeasured/unspecified aspects of practicum) which suggests the importance of the ST-AT relationship and the need for further research. Aspects of this study informed the design of this research, as noted in both the relationships and emotions sections of this review below.

A study examining a possible relationship between early signs of teacher burnout, ST perceptions of support and ST-efficacy was undertaken by Fives et al. (2007) who surveyed 49 STs in their final 12week practicum. They posed that STs may be particularly vulnerable to early experiences of burnout and burnout symptoms (such as emotional exhaustion, depersonalisation, and a sense of reduced personal accomplishment) because they are new to the professional demands of teaching and may have limited coping strategies. Fives et al. suggest it is during practicum that STs begin to develop adaptive or maladaptive coping strategies. They found STs' self-efficacy increased significantly over the practicum and reported the degree of AT involvement influenced the level of ST confidence and efficacy. Fives et al. found that a high degree of guidance and collaboration from ATs increased ST confidence and efficacy, thus creating a cushion for STs' development and lowering symptoms of burnout. These findings point to a significant relationship between efficacy and burnout: as efficacy increased, symptoms of burnout decreased. The focus of Fives et al.'s study also informed the design of this research project.

There is a considerable body of research that has investigated teacher efficacy, particularly in relation to individual teachers' self-efficacy. For example, in Canada, Bullock et al. (2015) surveyed 395 ECE teachers to examine possible links between teachers' years of experience, classroom management teacher-efficacy, and personality traits. They found personality traits were predictive of classroom efficacy above and beyond years of teaching. Extrovert and open personality traits increased teachers' efficacy and confidence in managing challenging classroom situations. The authors noted that teachers' self-efficacy beliefs seem to become more stable and resistant to change with time and experience.

In discussing the development and testing of a new teacher efficacy instrument, Tschannon-Moran and Woolfolk Hoy (2001) maintained teacher efficacy is related to school children's outcomes such as 
achievement, motivation and their own sense of efficacy. Teacher efficacy has also been associated with teacher effort, goals, level of aspiration, planning and organisation, openness to new ideas and willingness to experiment with practice. Teacher efficacy influences the degree to which teachers demonstrate persistence, resilience, and enthusiasm together with the level of criticism of students, time invested with struggling children and their commitment to the profession. Tschannon-Moran and Woolfolk Hoy (2001) suggest more serious consideration of the significant effects of teacher's beliefs may prompt changes to the way teachers are prepared and supported.

In a two-year ethnographic study of six experienced teachers within three Scottish schools, Biesta, Priestly and Robinson (2015) explored the role of teacher beliefs in agency. Biesta et al. maintained teacher agency is promoted by past experiences, oriented in future-focussed thinking and enhanced by engagement with the present. The authors suggest agency is highly dependent on the personal qualities, beliefs and values teachers bring to teaching. Biesta et al. suggested problems of agency lie in the tension between teachers' superficial understandings of discourses that inform and drive teacher's actions and the beliefs that teachers bring to their practices. They argue teachers' sense of agency can limit their actions when teachers are not clear about their own beliefs in relation to the value of education. Their data suggests that teachers struggle to recognise their teaching within a deeper consideration of the purposes of education, outcomes for students and their roles within this. In the absence of teacher involvement in "robust professional discourse, existing beliefs cannot be experienced as choices but appear inevitable" (p.638), resulting in a narrow framing of teacher goals, limiting possibilities and actions.

In a New Zealand study, Gibbons, Tesar, Steiner and Chan (2018) suggest teacher beliefs and agency are influenced by their ITE experiences. STs' ITE experiences may both promote or hinder ST agency with long lasting effects including building resistance to research partnerships and strategic silence during participation with wider educational issues. Assessments also impact on STs' perceptions of their agency, particularly during practicum. Gibbons et al. note the NZ Teachers Council's expectation of teachers' capacity to be "advocates and agents of their profession" (2018, p.51) while arguing that "the last two decades of neoliberalism within both the early childhood and tertiary policy domains has arguably quite strategically undermined the value and contribution of teacher voices" (2018, p.50). EC teachers' voices in policy and research could be enhanced by ITE programmes foregrounding ST agency through providing opportunities for ST's to exercise agency, strengthen commitment and encourage the desire to participate. 
Sumsion (2000) linked STs' beliefs to their capacity to become increasingly reflective during their ITE. In a qualitative study of 18 ECE STs over their four years of study, Sumsion found eight STs failed to become more reflective. Identified barriers limiting the development of ST reflection included STs' lack of commitment to teaching and to the value of reflection; perspectives of received knowledge; and perception of lack of ITE support. According to Sumsion, characteristics that may limit ST engagement in reflection include an orientation to extrinsic rather than intrinsic motivation; unproblematised views of teaching; concern with the technicalities rather than ethical dimensions of teaching; a limited view of their own efficacy; and little sense of being a member of a community of learners. Sumsion suggested ITE programmes need to explore sources of ST resistance to reflection, how ITE programmes may impede reflection via assessment practices, and ST perceptions of reflective frameworks. Sumsion invited ITE programmes to promote ST reflection in ways which "value the affective, intuitive and tacit aspects of reflection" (2000, p.212).

\section{Emotion - 'professional feeling'}

Two decades ago Sumsion claimed there seemed to be little understanding "about how or why emotions impact on learning to teach" $(1998$, p. 253) while maintaining that learning to teach is an emotional experience involving both struggle and effort. In the subsequent decades, emotion has come under increasing scrutiny in ST research.

Holland (2005) viewed emotion as both necessary and integral to knowledge construction and activation. She discussed the intersection between emotion, the body and social understandings as a way of knowing - what Ord and Nuttall refer to as 'embodiment'. Osgood (2010) explored the notion of ECE work as one of emotional labour managed within daily professional interactions. She suggested that the emotionality of ECE work depletes the reserves of teachers' "caring self" (p.130). Osgood also maintained that parents seek this caring quality and teachers intuitively extend this in their relationships with children. In her case study examining ECE teachers' construction of professional identity within three London 'nurseries', Osgood found that ITE programmes that cultivated selfawareness and critical reflection in teacher education produced teachers who were more highly valued in the profession and perceived as having professional confidence and who were able to understand and articulate alternative views and perspectives.

Student teacher emotion during practicum has been associated with socio-emotional adaptation (Caires, Almeida \& Vieira, 2012), burnout (Fives et al, 2007) and satisfaction and efficacy (Van Schagen Johnson et al., 2017). Furthermore, emotion has been examined in relation to STs' feelings of practicum success and confidence (Ord \& Nuttall, 2016), frustration (Sumsion, 1998) and as a cue for 
transforming frustration to success (Atiles \& Pinholster, 2013; Madrid, Baldwin \& Frye, 2013). These studies are described in this section.

Emotion is integrally linked to STs' experiences of burnout. Fives et al. (2007) describe burnout as including the sense that one has depleted their emotional resources and experiencing negative emotions towards students, community and self. They note, however, that while prevalent in the teaching profession, burnout is influenced by both resilience and early mastery experiences. Caires, Almeida and Vieira's (2012) quantitative study of 295 Portuguese STs examined STs' perceptions of their experiences during practicum and found the affective, social-emotional and relational aspects of ST experience lay at the heart of STs' perceptions of their achievement during practicum and, further, that STs' satisfaction in these affective domains, particularly their initial feelings of warmth, acceptance and inclusion were related to satisfaction and adaptation in other domains.

Van Schagen Johnson et al. (2017) explored socio-emotional facets of STs' practicum experience in relation to ST satisfaction and efficacy. Socio-emotional facets were measured by STs' reported feelings and perceived 'fit' with their AT. STs' feelings during practicum were measured on a 5-point Leikart scale using five emotions: anxious, energized, frustrated, quiet, and relaxed. The 'fit' or perceived congruence between the ST and AT teaching styles addressed communication with children; teaching style; best practice for children; behaviour management; goals for children; and child development. On average, the 32 STs felt energised and relaxed and were rarely frustrated, Van Schagen et al. reported. They also found that these feelings, on average, were related to a better 'fit' with their AT. In contrast, those STs who reported high levels of frustration had low levels of efficacy and satisfaction. The authors noted that although the ITE programme only placed STs in high quality ECE centres with experienced and supportive ATs, this may only account for some of their findings. For instance, they found overall ST satisfaction with practicum was a bigger predictor of efficacy beyond the socio-emotional factors (feelings and fit). Van Schagen Johnson et al. recommended further refinement of socio-emotional measures in future studies such as expanding the indicators of emotion to include multiple words that may be interpreted less ambiguously by ST's and the inclusion of interviews to gather more nuanced data on 'fit' (including feedback frequency and content). Aspects of this study helped inform my own study design.

Ord and Nuttall (2016) undertook a phenomenological study involving 13 ECE teachers who were in their first years of teaching. The researchers sought to understand the teachers' sense of preparedness to teach, gathering data from semi-structured interviews as participants graduated from their ITE programmes and again after six months experience as qualified teachers. The authors differentiated between STs' formal knowledge gained through their ITE programme and their practice 
knowledge or craft knowledge of ideas and strategies utilised in the real world of teaching. Ord and Nuttall also found within teachers' accounts that they moved between valuing formal knowledge (in the head) or 'cognisance' to the 'recognisance' of an embodied sense of knowledge. They suggest this process is one of not only thinking of oneself as knowledgeable but also encompasses the embodied sensation of learning and teaching coming together. Examples of this embodied knowledge included feeling confident and professional or the sense of things falling into place and meeting challenges with a belief that I can do this. Ord and Nuttall suggest that learning occurs through the relationship between STs' bodily sense of learning and their self-reflexivity. The authors argued that the learning of embodied knowledge be afforded more attention by ITE programmes and be seen as legitimate data from which to inform practicum assessment and development. They suggest that this is what STs might be meaning when they value practicum and practical experiences highly in their ITE programmes - that they are seeking a sense of fluid response and a sense of embodied knowledge rather than a stop and think stuttering of knowledge applied to practice.

Sumsion's (1998) Australian case study of two STs who discontinued their ECE ITE programme (despite good grades and practicum reports, one female, one male) was prompted by the emotional intensity of the STs' response to their practicum. She found that one ST's struggle and effort built her sense of inadequacy while the other's conflicting values with peers built his sense of isolation. Sumsion posed that beliefs and emotions are intertwined and together constitute a medium for "construction of meaning" (1998, p. 253), and that this interplay of beliefs and emotion is what contributed to the intensity of emotion experienced by the STs. She recommended ITE programmes might better understand STs' emotional frames of reference and epistemological beliefs as together these may be indicators of ST readiness to cope with the uncertainties and demands of teacher training. Sumsion argued exploring indicators of ST readiness required an ITE climate of trust and acceptance that these ST's may not have been able to access alongside a balance of sensitively timed ITE challenge and nurture.

Two separate in-depth accounts of individual ST's responses to their feelings of struggle and frustration as they examine their beliefs and develop their professional practices are presented by Madrid, Baldwin \& Frye (2013) and Atiles and Pinholster (2013). Madrid et al.'s six-month ethnographic study of one ST found the ST demonstrated critical emotional reflexivity as she responded to her feelings of discomfort. When confronted with discomforting ideas that prompted change in her practices, the ST viewed her emotional responses as signals for her to explore her core beliefs and assumptions. Madrid et al. note, while such reflexivity may create a sense of imbalance, that this is often, usual and necessary in learning as new information is considered. When this imbalance occurred for the ST in this study, she appeared ambivalent as she moved back and forth 
between views. Madrid et al. reported the ST's "willingness to get comfortable with uncomfortable emotions" (2013, p. 288) wasn't viewed as problematic by other teachers; rather it was viewed as a natural part of her teacher growth.

Madrid et al. (2013) maintained emotion shapes what we view as worthy of consideration yet little discussion is afforded as to how emotions might be utilised to inform teaching by ITE programmes. They argue there is a dominant discourse of positive emotion in ECE teaching (for instance, being warm, calm, and gentle) and less comfortable emotions such as stress, frustration and anxiety are masked due to either being viewed as 'unprofessional' or there being few opportunities to examine, consider and discuss these without judgement in the workplace. Madrid et al. suggest "learning how to feel as an educator is part of the hidden curriculum in early education programs" (2013, p.275). They maintain that using emotion as a signal to critically reflect is not about feeling 'bad' or 'good', but is more how emotion has the potential to prompt attention and motivate STs to take action and that through such reflexivity, "teachers develop an awareness that can help them resist, sort experiences and anxieties, fears and excitements, and use them in empowering ways" (p. 287). Furthermore, Madrid et al. argue that "too little attention has been given to the complexity of how emotions, perspectives and practices provide productive grounds for struggle and growth in ECE" (2013, p. 289) and recommend research into the range of emotions experienced by STs, how these are generated and what is needed to draw on these productively.

Another study of a ST's struggle with her discomforting emotions during practicum was undertaken by Atiles and Pinholster (2013). An action research study of one ST's experience with implications for ITE programmes, it describes the utilisation of critical reflection by the ST to take responsibility for her emotions during practicum, examine her tacit beliefs, and then develop and utilise strategies to build her efficacy. Atiles and Pinholster reported the ST moved from a sense of "drowning" (2013, p. 310) during practicum to a position of confidence. The ST in this study found it difficult to access support initially because she didn't want to reveal or be judged on her vulnerabilities. However, the ST devised strategies to assist herself, including journaling and positive self-talk; talking about her experiences with others; using video; and humour. These strategies enabled the ST to access support, remain positive, measure her progress and "lighten up and free up energy for a more positive assessment of the events and her abilities" (2013, p.316).

\section{Practicum Relationships}

Internationally, studies have found STs highly value the teacher development afforded by practicum experiences (Caires et al., 2012; Smith \& Lev Ari, 2005). Central to ST learning during practicum is the relationship developed between STs and those supervising their practicum experience. There is 
considerable consistency within NZ ECE practicum studies emphasising this aspect of ST experience and development (Aspden, 2017; Moles, Tanielu-Dick, Atiga-Anderson, Sauvao, Fuimaono, Ryan, de Rose... 2012; Murphy \& Butcher, 2013; Murray, 2015; Turnbull; 2005). These relationships have the capacity to both enable and hinder collaborative learning, development of ST confidence and subsequent risk taking (Loizou, 2011; Turnbull, 2005). This relationship appears to be largely influenced by ATs' pedagogical leadership, the support STs perceived they received and the relational trust engendered (Bryk \& Schneider, 2003; La Paro, Van Schagen, King \& Lippard, 2018; Murphy and Butcher, 2013; Murray, 2015).

In Israel, Smith and Lev Ari (2005) found 91\% of 480 STs surveyed viewed the practicum as highly significant in their preparation for teaching. STs reported ATS, VLs and peers were the main providers of support and feedback, while $74 \%$ valued feedback as the most useful tool for reflection. Caires et al. (2012) examined four dimensions of ST practicum experience: learning and supervision (ST teaching competencies, supervision and support); professional and institutional socialisation (school climate, warmth, respect and inclusion); emotional and physical impact (sleep, stress, diet, fatigue); and career aspects (alignment with the vocation and sense of teaching identity). Caires et al. found a positive correlation between each of the four dimensions, indicating ST satisfaction in one dimension was associated with satisfaction in the others.

The affective and relational aspects of ST experience appear to have played a central role in ST perceptions of their achievement during practicum in Caires et al.'s (2012) study. STs' initial experiences and subsequent feelings of warmth, acceptance and inclusion appeared highly significant to their development of relationships, response to supervision and development of their learning. Loizou (2011) found these initial ST perceptions significant for the development of AT-ST relationships, suggesting it is in this first meeting that STs judge the AT's manner, taking from it signals as to whether the AT is willing to support them during practicum. In New Zealand, Turnbull (2005) identified a welcoming experience and empathetic supportive AT are factors contributing to STs' professional agency in the practicum environment, while Murphy and Butcher (2013) found STs' perceptions of welcoming inclusion were further enhanced when extended by the whole teaching team.

While a positive, supportive practicum learning environment may contribute to ST perceptions of satisfaction and success, if the environment is tense or there is dissent among staff, STs may be unlikely to perform to the best of their abilities (Turnbull, 2005). Developing effective communication and relationships is potentially problematic in a stressful environment. Turnbull (2005) found aspects of ST communication that supported the development of professional relationships included giving 
and receiving respect; engaging in collaborative practice; articulating and discussing philosophy and pedagogy; and being able to interact in culturally diverse contexts. However, Turnbull noted when STs experienced a lack of appropriate AT feedback it appeared to be due to ATs avoiding giving difficult feedback in favour of maintaining the AT-ST relationship. Aspden (2017) maintained this occurs when the personal aspect of the AT-ST relationships took precedence over the professional.

La Paro et al. (2018) identified four inter-related elements influencing the ST-AT relationship: Communication; beliefs; perceived 'fit'; knowledge and learning. Communication informed and influenced the integration of existing and new beliefs with their knowledge of teaching. Communication then was a vehicle to explore experiences, beliefs and the creation of reciprocal understandings. Communication encompassed STs perceptions of support, feedback (frequency and method) and information sharing which may assist or hinder ST learning. Further, La Paro et al. (2018) suggested communication affects relationships within the practicum setting, learning within the setting and ST perceptions of practicum. They recommended ITE programmes could better prepare both ATs' and STs' practicum communication skills to enhance practicum relationships. Aspects of this study informed the current study design with regard to perceived 'fit' between ST-AT beliefs and practices.

STs seem to have clearly defined expectations of the relationship with their AT during practicum which appear related to the perceived authenticity of teacher relationships throughout the practicum setting. Murphy and Butcher (2013) found STs valued their practicum relationships when they were not only welcomed but included and respected as equals in the teaching team setting. They reported STs had clear opinions about their AT's pedagogical leadership, the value afforded to relationships and the larger team's teaching responses and team cohesion. STs who viewed the practicum setting as inspiring from the outset, recognised and responded to the consistency of their AT's professional caring manner, experience, modelling and knowledge as authentic. Turnbull (2005) also found STs evaluated the social environment and teaching competence within the whole practicum setting in determining the productiveness of the AT relationship and subsequent value of feedback. In Cyprus, Loizou (2011) found STs discerned the value of their mentor teacher and reported STs filtered the feedback they received by its perceived value. Murphy and Butcher (2013) noted STs valued meeting agreements which were honoured and characterised by an openness to explore ideas and challenges in a mutually respectful manner. Students stressed the importance of regular discussion and AT feedback which was specific and practice-oriented, including its role in building confidence (Loizou, 2011). 
Caires et al. (2012) suggest time is required to develop professional dialogues with supervisors, peers and other teachers which encourage self-reflection and exploration of perceptions and understandings, and that these dialogues are developed within these relationships. Smith and Lev Ari (2005) reported three-quarters of the STs surveyed found feedback a useful tool from which to develop their reflective skills (significantly more than reflective journal or portfolio work). This suggests STs (and ATs) who are afforded time for dialogue and deliberation, and who are open, reflective and curious about one another's views in professional dialogues may be less likely to experience problematic practicum relationships (Smith \& Lev Ari, 2005). These studies indicate STs' observations of and ability to build beneficial relationships during practicum appear influenced by their perception of the value and their trust in the pedagogical leadership evident to them in the STAT relationship.

It would appear STs identify and respond to explicit AT (and wider team) behaviours during their practicum which influence their practicum relationships and learning. Many of these behaviours are summarised by Bryk and Schneider's (2003) notion of relational trust. Trust is critical where the success of one's efforts is dependent on the contribution of others. This appears particularly relevant to STs' relationships during practicum and in New Zealand ECE settings where teachers work in teams. Bryk and Schneider maintained relational trust is built upon four key behaviours which engender trustworthiness: interpersonal respect (listening deeply to and valuing others contributions); regard for others (caring for others in both a personal and professional manner); competence in role (demonstrating trustworthiness in role, particularly in addressing lapses in expectations and obligations); and personal integrity (congruence between word and action). Bryk and Schneider found increased relational trust resulted in teachers' positive attitudes to risk, vulnerability and innovation and enhanced relationships, commitment and sense of community. These behaviours appear to be significant to STs in the practicum literature reviewed.

La Paro et al. (2018) found the inter-related elements of: communication; beliefs; fit; knowledge and learning can both create and hinder reciprocal understandings and behaviours in the AT-ST relationship. These elements, they maintain, are highly influential in the relationship, subsequent ST satisfaction and teacher-efficacy as they have the potential to strengthen, challenge and change ST practices. However, several studies highlight the influence of power in relationships between ATs and STs and the subsequent impacts upon relational trust (Loizou, 2011; Moles et al., 2012; Murray, 2015). Loizou (2011) maintained the ST-AT relationship is characterised by hidden power rather than reciprocal learning, noting the vulnerability of STs to feelings of acceptance and acknowledgment through support and feedback which affect STs sense of value and confidence. STs who asked for and specified the feedback they sought from the AT found that ATs didn't always appreciate or respond to 
these requests. Loizou also suggested ATs largely guided STs intuitively, based on their experience, knowledge and tacit beliefs, and rarely discussing or providing pedagogical rationales for their ideas and suggestions. She argued these examples of accepted power in the ST-AT relationship may result in tensions as tacit beliefs are challenged.

Equitable power relationships are particularly problematic when beliefs are challenged by the pervasive cultural discourse. Several New Zealand studies examining minority culture STs' perceptions of their practicum experiences found the ST-AT relationship was fundamental to positive outcomes for STs (Moles et al., 2012; Murray, 2015). Cultural understandings and practices as well as personal and professional skills played fundamental roles in the development of the ST-AT practicum relationship.

Moles et al. (2012) suggested New Zealand minority culture STs may be vulnerable during the practicum as they negotiate a path through the expectations of the ITE provider, the ECE setting and their own cultural knowledge within the practicum ST-AT relationship. The cultural competence of the AT also influences their perceptions and responses within the relationship. Moles et al. maintained multicultural STs may have different expectations of the relationship with their AT, suggesting STs view the responsibility to initiate communication lies with the AT. Moles et al. argued that ATs may need to consider ST relational behaviours through an alternative cultural lens. For instance, STs' possible reluctance to initiate dialogue or to ask questions may be due to them viewing this behaviour as intrusive or rude. Those ATs who were perceived as welcoming, who included STs in the team and who initiated an authoritative knowledge-based relationship with ST's were more likely to strengthen the students' confidence and perceptions of competence. For instance, STs valued ATs who were well informed about practicum expectations and assignments. Moles et al. suggested ATs need to proactively initiate and guide reflective discussion through questioning. Further, the authors reported STs value knowledgeable ATs who drive ST learning when developing practicum relationships. Whilst these findings are useful in understanding the experience of minority culture STs in New Zealand ITE programmes, the cultural backgrounds or numbers of STs in this study was unclear.

Murray's (2015) small study of three New Zealand Asian ECE ST-AT dyads found that STs required their AT have an understanding of the ST'S aspirations and measures of practicum success and that the AT relationship is critical to STs during practicum. The Asian STs in this study required ATs who invested time in developing dialogue, shared understandings and mutually respectful practicum relationships with them. Further, Murray reported STs did not consider the ITE assessment criteria as the most significant measure of their practicum success. Rather, these STs had more personalised goals such as increased teaching confidence, self-esteem and a sense of their AT's trust and respect. 
STs' measurement of success was enabled and supported through the goals they shared within this relationship rather than by the ITE practicum grade. Murray noted the tension of externally imposed criteria to measure the interpersonal aspects of ST practicum, suggesting such a fundamental aspect of practicum knowledge and subsequent success might be better determined by STs and ATs.

\section{Practicum Assessment}

Practicum literature indicates STs' concerns lie in opportunities to develop practice skills while strengthening their feelings of confidence in the practicum setting (Loizou, 2011; Murray, 2015; Turnbull, 2005). Caires et al. (2012) suggest research must acknowledge the affective and relational aspects that underpin the practicum and shape the way assessment is undertaken. ST confidence appears influenced by their relationship with the AT whilst the support and feedback received from ATs, other teaching staff, and VLs provide STs with formative assessment of their practices, thus contributing to their teaching development. Summative practicum assessment is also integral to the practicum. Both formative and summative assessments serve to support, guide and evaluate ST progress during practicum and are generally undertaken by both the AT and VL through observations, discussion with STs and written reports.

While STs are concerned about their relationship with, and support and guidance from their AT while on practicum, another aspect of ST concern is that of the VL's summative assessment. Several studies report STs may find this aspect of practicum stressful (Caires et al., 2012), inauthentic, confusing and unfair (Aspden, 2017; Moles et al., 2012; Murphy \& Butcher, 2013; Zhang, Cown, Hayes, Werry, Barnes, France \& TeHau-Grant, 2015). Aspden (2017) maintained practicum assessment is problematic, complex and sometimes flawed. Due to the highly individualised and subjective enactment of practicum assessment, participants' conflicting personal, professional and relational priorities can result in the stymying of ST agency during practicum.

Numerous studies have explored ST perceptions of the assessment process, recommending more preparation and support of those involved in assessment (Borko \& Mayfield, 1995), increased transparency (Aspden, 2017) and consistency (Turnbull, 2007) of practicum assessment practices. To address these issues, various studies have called for a revision of practicum assessment processes (Aspden, 2017; Turnbull, 2007; Zhang et al., 2015).

Over 20 years ago Borko and Mayfield (1995) examined the practicum experiences of four STs, 12 ATs and three VLs over three practicum placements and found few ATs or VLS were actively involved in the ST's learning, challenging teacher beliefs or guiding change in practice. Rather, Borko and Mayfield found ATs were generally uninvolved and ineffective in their mentoring roles with STs, largely due to their own learning beliefs and teacher education experiences. They also found AT 
involvement corresponded with ST learning. For instance, those ATs who believed in taking a more active role in ST's learning had more frequent meetings, for longer periods of time and provided more specific feedback and guidance. Both ATs and VLs appeared, by stressing their roles in building ST confidence, to avoid addressing or challenging ST beliefs and practices that may have enabled further ST learning. VLs in Borko and Mayfield's (1995) study had the least influence on ST learning; in fact, STs seemed to learn to expect even less from VLs than from their ATs, viewing VL feedback as unproductive due to the limited time invested, short length of observation and their perceptions that VLs lacked the subject expertise necessary to judge ST practice. These findings raise interesting questions of ST perceptions and acceptance of VL credibility within their teacher education programme.

Twenty years on many of the practicum and assessment issues identified by Borko and Mayfield (1995) remain. Despite more research investigating issues within practicum relationships, roles and assessment having been undertaken in the intervening years, the practicum assessment model appears to have remained unchanged with the issues identified by Borko and Mayfield continuing to impact on STs' development as teachers. This seems to signal that practicum experiences and challenges have been assumed as inherently normal or taken for granted (Aspden, 2017; Haigh \& Ward, 2004).

While meetings with and the time given to STs appear to be critical indicators of how specific their ATs and VLs feedback and guidance is likely to be (Borko \& Mayfield, 1995), participant silences throughout the practicum assessment process appear to surface repeatedly in the literature reviewed. To speak, to speak with acuity or not speak, appears to affect each participant in the assessment process for the same reason: 'risk'. This risk lies within the perceived roles, implicit beliefs and subjectivities of ATS, VLS and STs during practicum and has been attributed to a hierarchy of relationships inherent in the practicum assessment process (Aspden, 2017; Ortlipp, 2003; Turnbull, 2007; Zhang et al, 2015).

Turnbull (2005) suggested that the avoidance of addressing issues of practice or 'silence' within the ST-AT relationship is a consequence of wishing to maintain the relationship while Aspden (2017) proposed this occurs when the personal aspect of the ST-AT relationship takes precedence over the professional, resulting in a further perpetuation of this phenomenon. However, in the absence of high involvement of ATs and VLs in practicum relationships, Borko and Mayfield suggest the avoidance of open disagreement in assessment is due to a "shared desire to maximise comfort and minimise risks" (1995, p.516) during practicum. STs want to feel comfortable and confident whilst ATs and VLs want to be positive in order to build STs' confidence. 
Several studies, including two located in New Zealand, assert the avoidance of addressing practicum issues is a result of hierarchical power relationships (Aspden, 2017; Turnbull, 2007). This may result in STs focussing their practicum around practice performance (Aspden, 2017), and help explain VLs' reluctance to disturb practicum relationships (Ortlipp, 2003). Turnbull (2007) maintained that this power can be balanced in reciprocal exchanges such as the AT being an expert in practice while the ST is an expert in current theory, or STs asking their VL to undertake their assessment observation of the ST's practice in the VL's area of expertise and interest.

STs, ATs and VLs may 'silence' their own opinions due to the perceived 'risk' to themselves, the relationship or their perceived assessment role (Aspden, 2017; Ortlipp, 2003, 2009; Zhang et al., 2015). Aspden reported that high personal investment in the ST-AT relationship resulted in negligible amounts of specific assessment and feedback to the ST and, further, STs "were more likely to report positive assessment experiences when relationships were functioning well" finding such investment in maintaining relationships "can lead to compliance and inauthentic practice" (2017, p.134).

In their phenomenological New Zealand study of ECE practicum assessment, Zhang et al. (2015) found within the VL-AT-ST assessment relationship, that both ATs' and STs' judgements differed from the VLs, and that they employed what Aspden (2017, p.136) refers to as "tactical compliance" which further perpetuated a hierarchy of power. Zhang et al. (2015) questioned the VLs final role in judging the ST's success in the practicum assessment, suggesting that ATs have a better understanding of the STs' teaching development and fitness to teach than may be ascertained through the $V L^{\prime} s$ decisive one-hour observation. However, Aspden (2017) noted that in the New Zealand context, it is the regulatory and institutional requirements that have determined the VL role in summative assessment. Aspden maintained a shift in the hierarchy of assessment relationships is needed to address the context within which assessment is undertaken, the implicit beliefs of each participant, and the relationships that define each practicum triad while Zhang et al. (2015) suggest ITE programmes may need to develop alternative practicum assessment tools which enable greater shared roles within the triad assessment process.

Several studies have reported VLS do not always follow ITE procedures or reflect ITE practicum assessment criteria (Aspden, 2017; Turnbull 2007). It has been suggested VLs may mask or not attend to their subjectivities within practicum assessment (Aspden 2017; Ortlipp, 2009). Aspden (2017) advises that ITE programmes might openly attend to personal subjectivities in the assessment process, and better select, prepare and support STs, ATs and VLs in order to make assessment more transparent. She maintains ITE programmes need to prepare STs with the skills to participate fully in 
practicum assessment, to assure them "of the value of their active contribution to assessment, and to confront their perception that they cannot or should not challenge their assessment" (2017, p.140).

Studies report that STs view their role in assessment as limited with their perspectives not given high priority (Aspden, 2017; Zhang et al, 2015). Aspden (2017) found STs see their role in their assessment as limited but align their assumptions and beliefs to demonstrate what they believe the VL might view agreeably. STs can find it difficult to understand ATs' and VLs' assessment judgements and so can perceive these assessments as inconsistent (Aspden, 2017). STs and ATs have been found to silence their views during VL summative assessments rather than risk open disagreement and subsequent discussion (Aspden, 2017; Zhang et al, 2015).

STs and ATs appear to perceive the ITE programme's VL as driving the assessment process. Aspden (2017) reported ATs and STs accept this hierarchy within the triad assessment process despite the potential this may have to diminish the roles of STs' and ATs' voices, views and experiences. Some VLS have been reported consciously endeavouring to shift more power to STs by exchanging information about themselves, engaging in conversational questioning of the ST and developing an understanding of ST's beliefs and the practicum context (Aspden, 2017; Ortlipp, 2003).

Several studies examining VL assessment practices have found VLs have internal measures of assessment that may not be explicitly evident to ITE programmes, ATs or STs (Aspden, 2017, Ortlipp, 2003). The tension between VL support and the engagement of ATs and STs in practicum assessment processes becomes increasingly clear when the basis of VL's assessments are not made transparent to ATs and STs as indicated by Aspden who argued that "teacher educators define their roles in multiple and complex ways and in ways that may not align with the pre-conceptions and expectations that other participants have of them" (2017, p. 137). Ortlipp's (2003) examination of the Australian consensus model of triadic practicum assessment explored how $17 \mathrm{VLs}$ understood and practised practicum assessment. Her study found this model problematic in enabling STs' equitable voice while VLs reported a "reluctance to disturb relationships" (p.225). Ortlipp argued it is not the VL assessment that is problematic but the lack of awareness of VLs', ATs' and STs' understandings of inherent power relations present in the assessment process that impacts upon fairness, equity, open and critical dialogue, feedback, and the exploration of diverse views. Ortlipp maintained that the "subjectivities of participants and how they want to be seen and see themselves" (2003, p. 235) guides practicum assessment. Further to the previous study of 17 VLs, Ortlipp (2009) questioned the rationality of VLS using competency standards in practicum assessment, suggesting that VLs regulate and hide their 
subjectivities in order to appear fair and responsible. Ortlipp argued that acknowledging subjectivities in assessment might encourage increased transparency.

STs have been found to purposely demonstrate practices during assessment that they perceive to be within areas of VLs' expertise or interest to counteract the VL (and AT) power imbalance, utilising prior familiarity with VLs, peers and the "practicum grapevine" (Turnbull, 2007, p.179) to do so. To address some of the concerns about practicum assessment practice that emerged from their study, Borko and Mayfield (1995) suggested ITE programmes provide more AT preparation to increase their involvement in professional discussions and to challenge beliefs and practices. While Borko and Mayfeild acknowledged that VLs were always going to be assessors rather than supporters of STs due to their assignment of practicum grades, they suggested VLs could more usefully spend their time assisting ATs to develop their mentoring skills. Turnbull (2007) also noted inconsistent AT and VL assessment practices and suggested that ITE programmes must address this to support STS professional agency, as ATs and VLs have the power to either support or hinder such agency during the practicum. Building on these findings, Aspden (2017) posed that practicum assessment might ideally involve increasing collaboration which is both supportive and informative for STs and recommended using skilful assessors who are able to support STs to become increasingly agentic in feedback and professional dialogues. Achieving such change requires both imagination and innovation in how the assessment triad is conceived and enacted (Aspden, 2017). Several authors have suggested the implementation of practicum assessment requires re-thinking (Ortlipp, 2003), innovation (Aspden, 2017) and consideration of alternative assessment tools (Zhang et al., 2015) to promote more equitable contributions and shared understandings between triad members. The next section of literature review, video review, explores these issues.

\section{Video review}

Video provides evidence-based data from which teachers can review their teaching. There is considerable literature to support video review (VR) as an effective tool in aiding teachers' professional development and within pre-service programmes to support teachers' reflective analysis. Much of the literature has focussed on teachers' beliefs, analysis and reflection upon teaching strategies or on their students' learning and change in teacher practice (La Paro, Maynard, Thomason \& Scott-Little, 2012; Hatch, Shuttleworth, Jaffee \& Marri, 2016). This section of the literature review focuses specifically on studies located within the practicum component of ITE. While investigation of VR use in ITE programmes appears widespread internationally, there appears to be a gap in New Zealand research into this field of inquiry. 
STs appear to find VR both challenging and beneficial as a reflective tool. STs concerned with their appearance and self-image find VR confronting and stressful when first undertaking or sharing VR of their teaching (Bayat, 2010; La Paro et al, 2012; Navin, 2018). Bower, Cavanagh, Maloney and Dao (2011) found STs using VR were initially preoccupied by seeing themselves and undertook little analysis of their teaching until they had sufficient repeated practice in using VR. Atiles and Pinholster (2013) attributed a ST's feelings of reluctance to video-record her own practice to her feelings of selfconsciousness and vulnerability. STs who overcome these feelings may find the benefits of undertaking VR outweigh their anxieties. The ST in Atiles and Pinholster's study found VR invaluable to her awareness and adjustment of practices, stating by the end of practicum she wished she had shared her video with her VL as "the benefits of seeing myself and being able to make improvements completely overrode the feelings of embarrassment" (2013, p. 316). La Paro et al. (2012) found STs required inducements to undertake and share their teaching videos with peers and teacher educators and offered STs "points" (p.235) for preparation, participation in discussion and completion of tasks.

VR has been found useful in scaffolding STs' accurate self-evaluation of their teaching practices. Accurate self-evaluation is closely linked to reflective skills, intrinsic motivation and agency. Baecher, Kung, Jewkes and Rosalia (2013) explored the influence of VR on 31 STs' abilities to self-evaluate their own teaching. STs who had practiced assessing video models with evaluation rubrics and accompanying $V L$ ratings were better able to understand expectations of teaching practices than those STs who read descriptions of classroom teaching alone. Baecher et al. found STs who initially practiced evaluating other's teaching using VR were less inclined to over-inflate their self-evaluations of their own VR, more likely to make direct links to the assessment criteria and more likely to find their assessment matched their VL's. These STs were more likely to also shift their reflections from themselves to the learners and attributed this to the value of VR. In contrast, STs who had not practiced evaluating VR and who then undertook VR of their own teaching, made more generalizations about the effectiveness of their own teaching and did not indicate they valued VR as a tool for reflection. These findings could signal STs need structured practice and guided experience to utilise VR fully in developing their self-evaluation skills.

VR has also been found to help demystify the practicum assessment process for STs (Baecher et al., 2013). It has been suggested that STs are regularly assessed by others during their ITE programme yet the use of tools for accurate self-evaluation (Baecher et al., 2013) might support STs' confidence to be increasingly involved in discussion of teaching (Bower et al., 2011). Coffey (2014) found that some STs were able to identify aspects of their teaching in VR missed by their tutor while Baecher et al. (2013) suggest assisting STs to develop skills to accurately self-evaluate, utilise peer discussion to compare teaching perspectives and increase ST's involvement in their assessments. Baecher et al. argue 
increased ST involvement in assessment might then free-up teacher educators to play more of a supporting and mentoring role than just one of assessor during practicum.

Practicum video portfolios (Joseph \& Brennan, 2013) and on-line VR reflection blogs (Bower et al., 2011) have been explored in conjunction with supplementary peer coaching as a means for STs to evaluate their teaching and record their change and growth. Joseph and Brennan (2013) suggest this may allow for virtual supervision, particularly for distance STs, and provide an alternative to costly VL practicum visits. Both these studies (Bower et al., 2011; Joseph \& Brennan, 2013) maintain the similar levels of experience and knowledge of STs provides a safe non-judgemental context in which STs can explore and develop their practices with one another as they exchange video of their teaching. Both studies note STs needed practice with using VR technologies, repetition of analytical and reflective processes as well as effective frameworks through which to evaluate their own and other's video presentations.

VR may provide a space for STs to view their teaching as others do and 'see' strengths as well as deficiencies, thus developing STs' awareness and decision making in order to adjust their practices (Atiles \& Pinholster, 2013; Bower et al., 2011; Coffey, 2014). STs have found VR valuable in identifying areas of their teaching for improvement that they had previously been unaware of and to consciously choose to change (Atiles \& Pinholster, 2013; Coffey, 2014), while Bower et al. (2011) report repeated practice with VR assisted ST's sense of efficacy and ownership of both learning and change to their practice. Several studies have identified that VR helps STs to move their focus from their own teaching to children's learning (Atiles \& Pinholster, 2103; Baecher et al., 2013) while others have found such shifts are limited without practice and a clear structure for video review, analysis and reflection (Bower et al., 2011; Joseph \& Brennan, 2013).

Several studies have found STs' reflection is aided when undertaking VR of their own practice and self-identifying practices for development (Bayat, 2010; Bower et al., 2011; Coffey, 2014). Navin (2018) found STs reported VR highlighted discrepancies between ST perceptions of themselves and their actual practices, providing a different perspective from that remembered. STs reported VR provided unbiased feedback, helping them to reconcile verbal and written feedback with their actual performance and also providing a record of growth and change in practice (Coffey, 2014; Navin, 2018). However, Navin (2018) also found the 12 STs in her qualitative study focused on themselves (appearance, mannerisms, voice and confidence) and analysed their teaching superficially rather than directing deeper attention to their teaching strategies or children's learning. Bayat (2010) reported nearly half of the 14 STs in her action research study indicated they expected to learn little from the VR process while all STs indicated after VR they had much still to do to improve their practices. VR 
prompted STs to become more critical of their own skills, to notice deficiencies and begin to develop potential solutions according to Bayat (2010).

Not all studies have found VR to be effective in developing STs' productive reflection, however. Hatch et al. (2016) reported 63 STs' review of video of veteran teachers' lessons produced limited reflection and reinforced ST's initial teaching conceptions in discussion with peers. Hatch et al. attributed this to a lack of emphasis and guidance in developing "productive disagreements" in order to disrupt ST beliefs within the VR collaborative peer discussions (2016, p.283). Hatch et al. recommended ITE programmes consider discussion contexts and structured guides for STs' reviewing teaching video. Navin (2018) also found STs limited their reflection to an overview of the teaching context rather than individual children or specific teaching strategies, noting the need for ITE programmes to provide STs with structure and practice to utilise VR from an early stage in the ITE programme. In both these studies the contributions of teacher educators appear to have been limited in prompting further exploration of ST perspectives, perhaps indicating effective supervisor feedback may be influenced by ST peer group size. This issue is compared in the next study.

La Paro et al. (2012) explored 91 ECE STs' utilisation of VR of their own practices alone and then in small groups with a teacher educator. A variety of benefits for STs were reported by La Paro et al. including generation of more feedback for STs, STs' vicariously experienced many more ECE centre contexts, and peer feedback provided more points of view. La Paro et al. claimed video taught STs to actively observe and receive feedback about their practices and suggest studies such as this one might use ST generated video data to evaluate the effectiveness of ITE programmes.

The literature reviewed in this chapter indicates ST practicum perceptions of their experiences are influenced by a complex range of inter-related factors including: STs agency, beliefs and goals; emotion; relationships; and assessment practices. Teacher agency is influenced by beliefs (Bandura, 2001) subsequent motivation, goals, response to challenges (Dweck, 2000), adaptability (Caires et al., 2012) and satisfaction (Van Schagen Johnson et al., 2017). ST emotion may be utilised by both ITE programmes and STs to investigate beliefs and responses as cues to potential development (Madrid et al., 2013). Students' beliefs and emotions in turn may influence relationships (La Paro et al., 2018) and agency within the ECE profession (Gibbons et al.,2018). Practicum relationships also appear to be influenced by STs' perceptions of relational trust (Bryk \& Schneider, 2003) and opportunities afforded for support (Loizou, 2011). Assessment both enables and inhibits STs' perceptions during practicum and appear to be contingent upon the assumptions and subjectivities of each within the assessment triad (Aspden, 2017). The affordances of VR use during practicum while researched internationally are (so far) absent in NZ. The benefits (Bayat, 2010; Baecher et al., 2013; Coffey, 2014; Navin, 2018) and 
difficulties (Bower et al., 2011; Hatch et al., 2016; Joseph \& Brennan, 2013) of VR in teacher development may provide further opportunities to explore identified challenges to ST agency, the influence of emotion and impacts upon productive relationships and assessment experiences during practicum. 


\section{Chapter 3: Methodology}

This chapter outlines the research paradigm and methodology used in this study. The first sections discuss the research paradigm and design. These are followed by sections discussing the research procedures, data analysis, ethical considerations, and trustworthiness of the study.

\section{Research paradigm}

This research study is positioned within a constructivist paradigm. This is characterised by describing, understanding and interpreting multiple realities of the context bound experiences being studied. Such a paradigm emphasises the active role of the researcher in thinking about, interpreting and creating links in the data (Braun \& Clarke, 2006). This perspective stresses that meaning and experience are socially produced and include consideration of the "sociocultural contexts and structural conditions that enable individual accounts" (Braun \& Clarke, 2006. p.86). Merriam and Tisdell maintain this is a process of "constructing knowledge rather than finding it" (2016, p.9). Understanding a phenomenon through the perspective of the student teachers who live it, make sense of it, construct meaning from and interpret this personally, enables an understanding of participant experiences including their subjective experiences and internal states (emotions and thoughts). Thus, the focus of this study is the practicum experience from the students' perspective.

\section{Research design}

This research study is primarily qualitative with some data presented using quantitative methods. The key concern in this research design was to understand the participants' experiences from their perspective rather than that of the researcher (Merriam \& Tisdell, 2016). The research design took into account that the student teachers who would be invited to participate were also managing heavy study demands. Prior to gaining ethical consent for this project, a study that aimed to investigate student teachers' use of Video Review (VR) during practicum for reflection and discussion was designed and approved. Recruitment for this study was unsuccessful despite significant efforts with a number of targeted ECE student groups. Given the time constraints for postgraduate thesis submission, this project was abandoned and the current study developed. Suspecting students' reticence to be involved in VR may have been linked to the additional workload during practicum, it was hoped that utilising anonymous on-line surveys of students' practicum experience would be more appealing to student participation.

Research generally is characterised by asking a question, collecting data and analysing this to determine answers to the question posed. It may assist understandings of issues through an accurate accumulation of knowledge and assist improvement of practices by focussing attention on relevant 
policy decisions. Research steps whether qualitative or quantitative are dynamic (Creswell \& Guetterman, 2019) and as such can be undertaken using a number of methods and emphases.

Qualitative and quantitative research is commonly differentiated by numerical and non-numerical data to investigate a 'problem' posed by the researcher(s). Qualitative research is primarily concerned with exploring and developing an understanding of a phenomenon and participants' experience - why and how it occurs rather than how often. Qualitative research then is concerned with identifying and investigating the opinions, motivations and underlying reasons for a phenomenon. Such research also is characterised by inclusion of the researchers' subjective reflexivity and bias (Creswell \& Guetterman, 2019). In contrast, quantitative research generates numerical data or data reported as statistics to count or measure a research problem in proving/disproving a hypothesis (Creswell \& Guetterman, 2019). Quantitative research is used to describe trends, relationships among or between variables and arises primarily from a research focus on the need for an explanation of a phenomenon. Evaluation criteria of quantitative research assumes an objective and unbiased approach to research and researcher (Creswell \& Guetterman, 2019).

The central research questions for this study are "What are ECE Student Teachers" perceptions of the significance and challenges of their practicum experience " and, "What are ECE student teachers' views about the potential inclusion of Video Review (VR) within the practicum?"

Survey design

Survey questions in this study were designed to provide prompts for student teachers to recall, describe, explain and revisit some of their practicum experiences. These included six aspects: how students view the significance of practicum in their teacher training; what they see as challenging; what their priorities for development are, how they utilise these goals and the degree of reflective practice about goals/ challenges; how they feel on practicum and what influences this; how they experience AT and VL support and guidance; and, how they view VR and perceive its relevance, challenges and effectiveness may be to them during practicum.

Online surveys have a number of advantages in recruiting research participants and gathering research data (Andres, 2012). They are self-administered and may be smart phone compatible so are able to be completed at the respondent's leisure where and when they wish and as such may elicit thoughtful and reflective responses. This type of survey can be conducive to exploring sensitive topics where respondents may in other circumstances feel vulnerable to judgment, for instance, face to face with an interviewer or discussed with a peer. Online surveys are inexpensive, environmentally friendly, and able to be administered and completed quickly. While online surveys can ensure participant anonymity, there is also no guarantee, however, that the survey is actually completed by 
the respondent or that they read questions thoroughly and provide considered responses (Creswell \& Guetterman, 2019). Andres (2012) suggests that individuals within organisations where digital technology use is wide spread are good candidates for online survey participation, though

“...populations most likely to be appropriate for web surveys probably suffer from email and possible web survey fatigue... only the most salient surveys will be completed" (p.52, 2012). Creswell and Guetterman (2019) note that online surveys can be subject to technical difficulties.

\section{Research Procedures}

Two surveys were developed utilising the Qualtrics online survey tool. Survey questions were informed by the researcher's prior Master's study, research literature and her professional experience as a VL supporting, mentoring and assessing ECE students during their practicum. The questions focused on the students' perceptions of: the significance of the practicum in their teacher development; their goals, challenges and emotions; relationships with AT, centre staff and VL; assessment; and, their views about video review as a potential tool in practicum assessment. Survey questions included: multiple choice; Leikert matrix tables with 3-5 point ratings; and text entry options. To mitigate participant effort in completing the survey(s), surveys were intended to take 1020 minutes to complete. A draft survey was piloted with five ECE teachers who volunteered to test response times and coherence of survey questions prior to the commencement of this study.

The pre-practicum survey asked students to recall their earlier experiences on practicum while the post-practicum survey asked students about their most recent practicum experience. The surveys were timed and administered to try to capture as many participants as possible. Thus, the second survey contained additional questions for those having completed the first survey as well as a complete question set for those undertaking the survey for the first time. Skip logic was used for students returning to complete the second survey so that they didn't repeat previously answered questions. Providing two surveys was intended to potentially build a larger number of respondents as well as providing additional data about student teachers' experiences in their latest practicum. It was hoped that students completing the first might wish to complete the second (though this was not required).

The pre-practicum survey contained a total of 21 questions and the post-practicum survey 36 questions. Of the 36 questions, only 15 were for those having already completed the pre-practicum survey. These additional 15 questions focussed on self-efficacy (experiences with AT and VL) and asked again about their thoughts about potentially utilising VR on practicum. In addition, student demographics were collected from each student, providing a picture of the characteristics of 
participants. Questions included students' age range, ethnic background, gender, year of study and practicums completed. Appendix B., provides the survey questions.

\section{Participants}

All students in their second and third years of study within a three-year undergraduate ECE ITE programme were eligible to participate in the two anonymous online surveys. These students were invited because they undertook a six-week practicum over the same period each year, and because they had had sufficient experience of student practicum experience to fully respond to the survey questions, having completed at least two practicum in their training.

\section{Recruitment}

Recruitment was undertaken through the ITE provider in order to maintain the privacy and anonymity of both participants and those who chose not to participate from the researcher. The recruitment invitation and participant information email (see Appendix B) was forwarded to students by an ITE programme administrator with a link to the online survey one week before practicum and on completion of practicum six weeks later. Each survey was open for respondents for three weeks. In the post-practicum survey period, a reminder email was distributed to students at weekly intervals.

\section{Data analysis}

This study generated both qualitative and quantitative data for analysis. Prior to the analysis of the qualitative data, the data was cleaned to remove extraneous entries such as "not applicable" from text entries where there was a forced response. An inductive approach to thematic analysis of qualitative data was utilised to generate understanding of STs' experiences. From patterns in the data and a focus on interpretation of latent themes, insight into STs' experiences was sought (Braun \& Clarke, 2006). Merriam and Tisdell (2016) suggest analysis occurs throughout data collection and is creative, iterative and holistic. Braun and Clarke argue that thematic analysis is a method in its own right "for identifying, analysing and reporting patterns (themes) within the data" (2006, p.79). This thematic analysis is a recursive process with the analysis produced over time in an ongoing reflexive research dialogue (Braun \& Clarke, 2006). Text entries within the survey responses were coded for themes and recoded utilising an inductive approach. Quantitative data was analysed and reported as descriptive statistics to show simple summaries of students' collective reported experiences. These help to show general measures, patterns and features of students' collective experiences.

\section{Ethical considerations}

Students were advised that they could complete one or both of the surveys offered, that participation was voluntary, anonymous and consent would be deemed in their optional final submission of their 
survey responses. Students were offered entry into two draws (one each survey) for $\$ 100$ grocery or book voucher on completion of the survey as both a participation incentive and acknowledgment of their contributions. Students wishing to enter this draw were directed to a separate survey site via a link at the end of the survey where they could provide their email address, ensuring data could not be matched to participants and to protect participant anonymity. This study was approved by the VUW Human Ethics Committee (application number \#0000026822).

\section{Trustworthiness}

Johnson and Christensen maintain qualitative research trustworthiness or validity is defined by research which is "plausible, credible, trustworthy, and therefore defensible" (2014, p.299). This can be maximised by checking the descriptive, interpretive, theoretical, internal and external factors influencing the construct, analysis and reporting of the research (Johnson \& Christensen, 2014). One of the main threats to research trustworthiness is researcher bias. This may be mitigated by rigorous researcher reflexivity, peer review, discussion and checking, and research journaling. One key element is acknowledgement of the positioning of the researcher and their potential bias.

Researcher reflexivity was utilised to continually check for 'confirmation bias'. Braun and Clarke (2006) suggest the most basic challenge in being reflexive is reconciling engaging with the data with the impossibility of abandoning previous knowledge and experience, while also being clear about what the researcher is doing, why and how. Rather than trying to eliminate bias that may impact on the analysis, Merriam and Tisdell (2016) suggest researchers identify and monitor this in the research and make explicit how this might impact upon or influence the collection and analysis of data.

My experience over 20 years of working directly with ECE pre-service teachers on practicum has afforded me experience in the process of observing, reflecting upon, discussing and recording teaching with students and peers. This work frequently provokes an examination of my own teaching practice, values, assumptions and beliefs and I recognise that this background holds potential to shape my interpretations in, and the direction of, the study (Merriam \& Tisdell, 2016).

Frequent meetings to discuss, explore and examine assumptions were undertaken with my research supervisor. These and other ideas as they emerged were recorded and revisted in a research journal throughout the process of this study. These assisted in my researcher reflexivity and provided records of my decision making throughout the research process of the study.

This chapter has described and discussed the methodology of this study: research paradigm; design; procedures; data analysis; ethical considerations; and trustworthiness of the study. The next chapter describes the results of data generated by this study. 


\section{Chapter 4: Results}

The data presented in this chapter have been generated from a sample of twenty student teachers enrolled in an undergraduate degree programme in a New Zealand university. Two anonymous online surveys were conducted between October and December 2018 prior to and after students' sixweek practicum.

The results are presented in five sections reflecting the survey content: participant demographics; perceived significance of practicum, goals and challenges; student emotions on practicum; Associate teacher and Visiting lecturer assistance and feedback; and, perception of video as a tool on practicum.

Fifty-three student teachers were eligible to participate in the study ( 28 third years and 25 second years). Fourteen completed the pre-practicum survey (twelve of whom returned to answer additional questions in the post-practicum survey) and six students completed the post-practicum survey. Six further students opened the second (post-practicum) survey but did not complete any responses. Response rates to individual questions vary as some questions were not set to a force response requirement.

\section{Demographics}

All participants identified as female and had completed between two and five practicums in their teacher training. All participants were enrolled in a three-year BEd(Tchg)EC Degree. Sixty-five per cent of participants were third years, 30\% were second years and 5\% identified as "other" - a third-year student undertaking a second year practicum. Ages of participants ranged from under 20 years to $41-$ 50 years. Almost all respondents were aged under 30 years $(N=17,85 \%)$ with only three students aged between 31 and 50 years.

\section{Table 4.1 Student age}

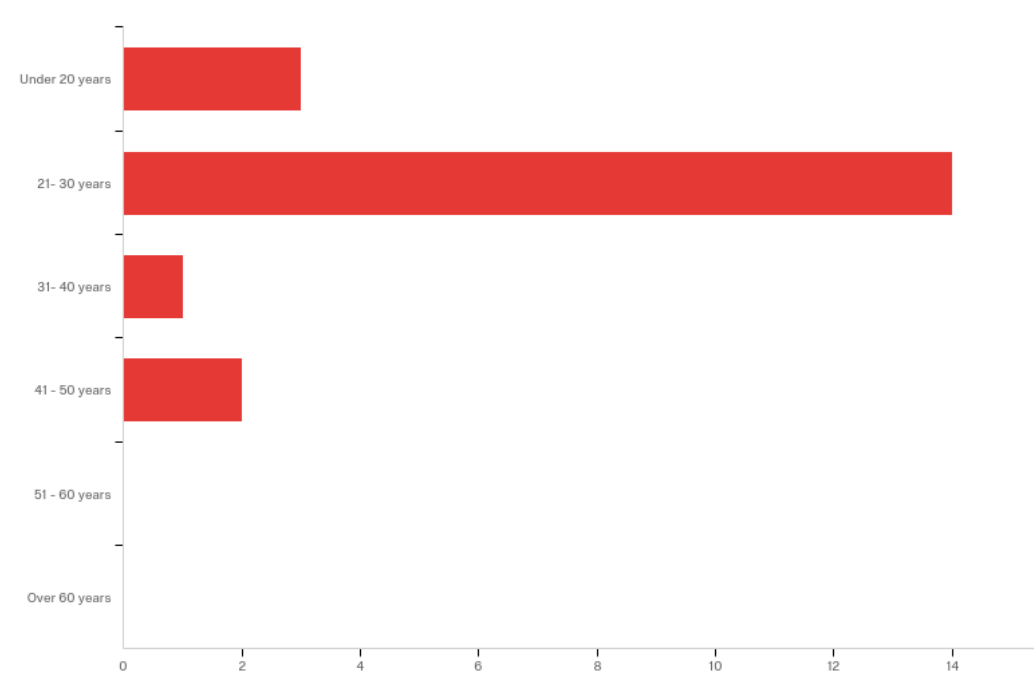


The ethnicity of participants was diverse. Half of the sample identified as Pakeha New Zealander. The remaining participants included Asian, Maori, European, Pasifika and "Other" (one Australian and one "New Zealand European and Dutch").

Table 4.2 Student ethnicity

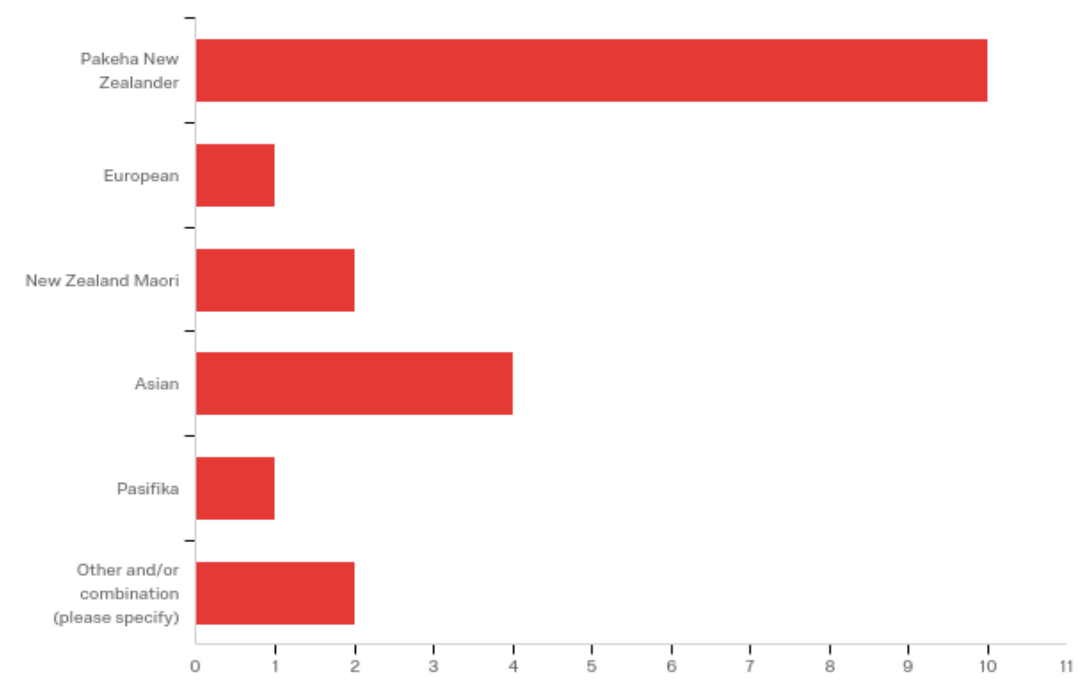

Significance of practicum, goals and challenges

The students were asked to rate the significance of aspects of their practicum. Table 4.3 shows $95 \%$ of students identified the practicum as very significant ( $5 \%$ quite significant) in their teaching development. Gaining experience working with children and in a team of ECE teachers were also rated highly by respondents. Students perceived opportunities to reflect on practice, develop confidence and receive feedback on their teaching as less significant although it was still rated "very significant" by $75-70 \%$ of respondents.

Opportunities to apply theory learned in classes, to discuss their teaching practices in context, and to manage challenges constructively, while rated very significant by $55 \%-50 \%$ of students, were less significant to the participants than the other items. Interestingly, while $70 \%$ of students view feedback on their teaching as highly significant, only $55 \%$ perceived discussion of their practices to be an important aspect of practicum learning. This finding may indicate respondents viewed their role in discussion as less important or that they were less comfortable discussing their practice.

Three responses were recorded in the text entry option of "other" as "very significant". Two responses included: "Observing teachers and their interactions with children" and "Get to see a variety of philosophies and practice" indicating that encountering opportunities to observe a wide range of teaching practices was a significant aspect of teaching development to these students. The third 
response, "Feeling included in the teaching team as a student teacher" appeared particularly significant for one student. This issue was reported in her responses to several other survey questions where it emerged she had not always felt welcomed or included and had been failed on her first practicum by her AT after being told she was "doing fine".

Overall, these responses indicate that students highly value and recognise the importance of their practicum to their teaching development in providing opportunities to gain direct experience working on their professional skills.

Table 4.3 Aspects of practicum: student perception of significance to their teaching development

\begin{tabular}{|c|c|c|c|c|c|c|c|c|c|}
\hline \multirow{2}{*}{$\begin{array}{r}\text { Please indicate how significant each of } \\
\text { the following aspects are to your } \\
\text { development as an Early Childhood } \\
\text { teacher }\end{array}$} & \multicolumn{2}{|c|}{$\begin{array}{r}\text { Very } \\
\text { significant }\end{array}$} & \multicolumn{2}{|c|}{$\begin{array}{r}\text { Quite } \\
\text { significant }\end{array}$} & \multicolumn{2}{|c|}{$\begin{array}{r}\text { A bit } \\
\text { significant }\end{array}$} & \multicolumn{2}{|c|}{$\begin{array}{l}\text { Not at all } \\
\text { significant }\end{array}$} & \multirow{2}{*}{$\begin{array}{r}\text { Total } \\
\#\end{array}$} \\
\hline & $\%$ & \# & $\%$ & \# & $\%$ & $\#$ & $\%$ & $\#$ & \\
\hline Going on practicum & 95 & 19 & 5 & 1 & 0 & 0 & 0 & 0 & 20 \\
\hline $\begin{array}{r}\text { Gaining experience working with } \\
\text { young children }\end{array}$ & 90 & 18 & 10 & 2 & 0 & 0 & 0 & 0 & 20 \\
\hline $\begin{array}{r}\text { Gaining experience of working in a } \\
\text { team of ECE teachers }\end{array}$ & 85 & 17 & 15 & 3 & 0 & 0 & 0 & 0 & 20 \\
\hline $\begin{array}{r}\text { Reflecting on my practice as a } \\
\text { student teacher }\end{array}$ & 75 & 15 & 20 & 4 & 5 & 1 & 0 & 0 & 20 \\
\hline $\begin{array}{r}\text { Opportunities to develop } \\
\text { confidence }\end{array}$ & 75 & 15 & 20 & 4 & 5 & 1 & 0 & 0 & 20 \\
\hline $\begin{array}{r}\text { Get feedback on my teaching } \\
\text { practices }\end{array}$ & 70 & 14 & 25 & 5 & 5 & 1 & 0 & 0 & 20 \\
\hline $\begin{array}{l}\text { Putting the theory learned in my } \\
\text { university classes into practice }\end{array}$ & 55 & 11 & 40 & 8 & 5 & 1 & 0 & 0 & 20 \\
\hline $\begin{array}{l}\text { Opportunities to discuss my } \\
\text { teaching practices in context }\end{array}$ & 55 & 11 & 40 & 8 & 5 & 1 & 0 & 0 & 20 \\
\hline $\begin{array}{l}\text { Opportunities to manage } \\
\text { challenges constructively }\end{array}$ & 50 & 10 & 50 & 10 & 0 & 0 & 0 & 0 & 20 \\
\hline Other (please elaborate below) & 15 & 3 & 0 & 0 & 0 & 0 & 0 & 0 & 3 \\
\hline
\end{tabular}


Nineteen students provided additional text entries elaborating on aspects of practicum significant to them in their teaching development. The importance of developing their skills while experiencing every day centre life was a consistent theme in students' entries. Although students appeared to see applying theory learned in classes as less significant (see Table 4.4), many referred to the importance of opportunities to experience "real teaching" rather than hearing or reading about someone else's experience.

"It gives you real working experience of how to work with children. There is only so much you can learn in class, but a lot of the learning is done by being hands on and working with other staff learning how to face difficult situations you may only hear about in class"

"The most important aspects are putting what has been learnt in class into place, to be able to relate and reflect"

Students' comments also revealed their focus lay in working with children, participating within the team and developing relationships with families, for example:

"Observing how centre life is run on a daily basis, witnessing how to work professionally with other teachers, how to engage with children and their interest and talking with parents and getting to know them. Putting theory into practise and discovering what is important to me and my beliefs".

A significant number of students referred to the importance of support and feedback from Associate teachers and Visiting lecturers in their entries, for instance:

"In my two previous placements I was more or less left to my own devices as my AT felt I was confident enough to do so because I had worked as a relief teacher previously. However, I feel that more mentoring, constructive feedback and help to improve my practice would be much more helpful. Also, opportunities to manage challenges with support and back up is very important to me."

Several students included the development of their own philosophy of teaching and professional behaviours as a significant aspect of their teacher development on practicum:

"Getting to work with a range of teachers in a range of centre's who all have different philosophies and experiences".

"Learning further within a teaching team and refining my own teaching philosophy and practice". 
For two students, the growth of their cultural understandings was the most important aspect of their teacher development during practicum:

"Learning about other cultures"

"The diversity within centre communities and classes"

These entries indicate students view their practicum as important opportunities for "real life" teaching experiences and growth of their professional knowledge, skills and relationships.

\section{Student teacher practicum goals}

Students were asked to indicate the nature and use of their practicum goals. Table 4.4 shows students were most likely to share their goals with their Associate teacher and to a lesser extent their Visiting lecturer. Students reported their practicum goals were more likely to be personal goals and general ideas about what they wanted to achieve than professional goals, although it wasn't clear how students differentiated between these. Students also indicated they were least likely to share their goals more widely with other teachers at the centre. This may be due to an unwillingness to risk judgment, a desire not to align themselves with teachers who students may view as less involved in their assessment, or simply having fewer opportunities to discuss their teaching with teachers during shared lunch breaks or meetings.

Table 4.4 Student practicum goals (20 respondents)

\begin{tabular}{|r|c|c|}
\hline When you were on practicum, did you? (select all that apply) & $\%$ & $\#$ \\
\hline Share my goals/ideas with my Associate Teacher & 80 & 16 \\
\hline Identify personal goals for myself (e.g., personal competence, performance, confidence) & 75 & 15 \\
\hline Shave some general ideas about what I would like to achieve but don't frame these as goals & 70 & 14 \\
\hline Share goals/ideas with my Visiting Lecturer(s) & 70 & 14 \\
\hline Identify professional goals for my own teaching development (e.g., curriculum, workload, & 65 & 13 \\
\hline Share my goals/ideas with other teachers in the centre & 20 & 4 \\
\hline
\end{tabular}

Participants were asked to indicate the frequency and manner in which they utilised their practicum goals. Reflection on their progress in achieving their goals (see Table 4.5) was the most common practice reported by students "all the time" or "often" (N=20; 100\%). Students reported they 
frequently developed strategies to achieve their goals ( $N=16 ; 80 \%)$, built on goals set from one practicum to the next $(\mathrm{N}=16 ; 80 \%)$ and revisited their goals to see if these were still relevant during their practicum $(\mathrm{N}=15 ; 75 \%)$.

However, twenty percent $(\mathrm{N}=4)$ of students reported they "hardly ever" developed strategies to achieve their goals, built on their goals from one practicum to the next or revisited goals to see if they were still relevant. One student identified she "Never" revisited her goals . This could suggest that some students may not view their practicum goals as instrumental to their development of practice and/or view their goals as a course requirement rather than an important tool in their continual teacher development.

Sixty-five percent of participants reported their goals remain the same "all the time" or "often" from one practicum to the next $(\mathrm{N}=13)$. This result might imply that students lack strategies to measure their progress or feel they aren't making progress or that their goals are so broad that they are held constantly as unachieved/aren't progressed.

Table 4.5 Student utilisation of their practicum goals

\begin{tabular}{|c|c|c|c|c|c|c|c|c|c|}
\hline \multirow[t]{2}{*}{ To what extent do you? } & \multicolumn{2}{|c|}{$\begin{array}{l}\text { All the } \\
\text { time }\end{array}$} & \multicolumn{2}{|c|}{ Often } & \multicolumn{2}{|c|}{$\begin{array}{r}\text { Hardly } \\
\text { ever }\end{array}$} & \multicolumn{2}{|c|}{ Never } & \multirow{2}{*}{$\begin{array}{r}\text { Total } \\
\#\end{array}$} \\
\hline & $\%$ & \# & $\%$ & \# & $\%$ & \# & $\%$ & \# & \\
\hline Reflect on my progress in achieving my goals/ ideas & 25 & 5 & 75 & 15 & 0 & 0 & 0 & 0 & 20 \\
\hline Develop strategies to help me achieve my goals/ideas & 20 & 4 & 60 & 12 & 20 & 4 & 0 & 0 & 20 \\
\hline $\begin{array}{r}\text { Build on the goals I set for one practicum in my next } \\
\text { practicum }\end{array}$ & 15 & 3 & 65 & 13 & 20 & 4 & 0 & 0 & 20 \\
\hline Re-visit my goals/ideas to see if they are still relevant & 15 & 3 & 60 & 12 & 20 & 4 & 5 & 1 & 20 \\
\hline $\begin{array}{r}\text { Find my goals/ideas remain the same from one } \\
\text { practicum to the next }\end{array}$ & 10 & 2 & 55 & 11 & 35 & 7 & 0 & 0 & 20 \\
\hline
\end{tabular}

All twenty participants provided additional text entries describing their goals for practicum which included wide ranging and highly personalised challenges. A theme of moving from thinking and talking about teaching to the practice of working at teaching and learning within Centre environments was evident, for instance:

"Developing practical skills, we spend so much time learning academic theory but don't learn the practical skills as often as I'd like to".

"Being more assertive in my practice with children in a way that is respectful, and in a way that they see that I am looking out for their best interests..." 
Building professional relationships with the teaching team and children's families, developing skill in pedagogical documentation, refining facilitation of children's learning and practicing Te Reo were recurrent sub-themes in the students' entries, for example:

"Gaining confidence to build strong relationships with parents and whanau and getting better at writing learning stories".

"One of my goals is to be able to identify through children's plan(s) which areas of the curriculum they are engaging with and to be able to extend this knowledge as appropriate" "My knowledge and practice of Te Reo Maori and putting it in practice".

The development of confidence was mentioned frequently by students across a range of practice areas:

"My confidence with speaking Te Reo"

"Confidence when speaking to parents"

"Confidence to set out tasks/activities independently"

For several students, developing skills in working with larger groups of children were important goals during practicum which may indicate their perception of desirable professional skills in this latter stage of their training:

"Class control when it came to large (20+) mat times"

"I would like to develop my confidence in holding a mat time or reading engagingly with the whole or most of the group".

Some students expressed concern in developing the "how to" or "not" of teaching skills as related to their practicum goals, for example:

"How to handle tough and difficult situations with either children or families"

"Not talking too fast or leaving enough time after I ask questions".

"I am concerned about developing a pattern where I am too comfortable with the goals I have achieved and never look to improve on myself".

"My ability to teach outdoors. I prefer to be an indoor teacher". 
The only anomaly was a student who reported she was "unsure" what she was most concerned with developing within her practices during practicum.

While the goals students identified for themselves on practicum were wide ranging, they were broadly concerned with the development of their teaching knowledge, skills and confidence in their roles within the "real teaching" context of Early Childhood settings.

These responses, in conjunction with $40 \%$ of students reporting they did not always include their goals within their practicum assignments (see Table 4.5 ) and $20 \%$ of students reporting they hardly ever develop strategies to assist their achievement of practicum goals (see Table 4.6), raise questions about the extent to which students' practicum goals are monitored in their teacher development, and whether students are required to provide evidence of their progress or review their goals throughout their ITE programme.

\section{Practicum Challenges}

Students were asked to rate the perceived level of challenge within aspects of their practicum (see Table 4.6). Combining extremely challenging and challenging categories, using assessments of children's learning to plan learning experiences was a significant challenge for $85 \%$ of students, as was managing workload and writing assessments of children's learning ( $N=15 ; 75 \%)$. Managing their own wellbeing, completing assignments and utilising appropriate teaching strategies was a challenge for $70 \%$ of students $(\mathrm{N}=14)$.

Building relationships with parents was an aspect of practicum that provided a significant contrast of student reporting. It was extremely challenging for $25 \%$ of students, challenging for $40 \%$, while $35 \%$ reported this was not at all challenging. This result may reflect the confidence and life experience of the sample (85\% being under 20-30-year olds).

Working on their practicum goals and responding to children was also challenging for $65 \%-60 \%$ of students. Visiting lecturer assessments and their relationship with their Associate teacher was reported as less challenging (50\%) though visiting lecturer assessment was extremely challenging for $15 \%(N=3)$ of students.

The least challenging aspects of practicum reported by students included the development of their relationships with the teaching team (55\% not at all challenging), reflection on their practice $(55 \%$ not at all challenging), and ability to build relationships with children ( $90 \%$ not at all challenging). 
Students' ratings of challenging aspects of practicum indicate they found practising planning for and responding to children's learning while managing their study workload and personal wellbeing most challenging. Least challenging aspects of practicum for students were reported as managing relationships with the wider teaching team, reflection and developing relationships with children.

Table 4.6 Practicum challenges

\begin{tabular}{|c|c|c|c|c|c|c|c|}
\hline \multirow{2}{*}{$\begin{array}{r}\text { How challenging did you find the following on this } \\
\text { practicum? }\end{array}$} & \multicolumn{2}{|c|}{$\begin{array}{l}\text { Extremely } \\
\text { challenging }\end{array}$} & \multicolumn{2}{|c|}{ Challenging } & \multicolumn{2}{|c|}{$\begin{array}{l}\text { Not at all } \\
\text { challenging }\end{array}$} & \multirow{2}{*}{$\begin{array}{r}\text { Total } \\
\end{array}$} \\
\hline & $\%$ & \# & $\%$ & \# & $\%$ & $\#$ & \\
\hline $\begin{array}{r}\text { Using assessments of children's learning to plan } \\
\text { learning experiences }\end{array}$ & 20 & 4 & 65 & 13 & 15 & 3 & 20 \\
\hline Managing my workload and time & 20 & 4 & 55 & 11 & 25 & 5 & 20 \\
\hline Writing assessments of children's learning & 15 & 3 & 60 & 12 & 25 & 5 & 20 \\
\hline $\begin{array}{r}\text { Managing my own wellbeing (e.g., my energy, } \\
\text { stress levels, confidence and feelings of } \\
\text { competence) }\end{array}$ & 20 & 4 & 50 & 10 & 30 & 6 & 20 \\
\hline Completing the practicum assignments & 10 & 2 & 60 & 12 & 30 & 6 & 20 \\
\hline $\begin{array}{r}\text { Being able to select and use different teaching } \\
\text { strategies with children }\end{array}$ & 10 & 2 & 60 & 12 & 30 & 6 & 20 \\
\hline Building relationships with parents and whanau & 25 & 5 & 40 & 8 & 35 & 7 & 20 \\
\hline $\begin{array}{r}\text { Creating and facilitating relevant learning } \\
\text { experiences with children }\end{array}$ & 10 & 2 & 55 & 11 & 35 & 7 & 20 \\
\hline $\begin{array}{r}\text { Working on the aspects of my practice I want to } \\
\text { develop }\end{array}$ & 5 & 1 & 60 & 12 & 35 & 7 & 20 \\
\hline Managing children's behaviours and wellbeing & 5 & 1 & 55 & 11 & 40 & 8 & 20 \\
\hline $\begin{array}{r}\text { Visiting Lecturer assessments (observation, } \\
\text { discussion, report) }\end{array}$ & 15 & 3 & 35 & 7 & 50 & 10 & 20 \\
\hline $\begin{array}{r}\text { Managing the relationship with my Associate } \\
\text { Teacher }\end{array}$ & 5 & 1 & 45 & 9 & 50 & 10 & 20 \\
\hline $\begin{array}{r}\text { Managing the relationship with the other teachers } \\
\text { in the team }\end{array}$ & 10 & 2 & 35 & 7 & 55 & 11 & 20 \\
\hline Being able to reflect on my practices & 5 & 1 & 40 & 8 & 55 & 11 & 20 \\
\hline Building relationships with children & 0 & 0 & 10 & 2 & 90 & 18 & 20 \\
\hline
\end{tabular}


All twenty participants commented upon the aspects of practicum they found most challenging. The nature of the challenges reported were highly individualised. Predominant areas of challenge reported by students included: Writing assessments of children's learning, determining teaching strategies and facilitating children's learning; completing assignments; building relationships with their AT; developing confidence while managing their feelings; and, utilising Te Reo Māori. Across these issues, however, developing confidence in professional behaviours with support and feedback was an underlying theme of entries, for instance:

"Managing my own feelings of confidence and competence. I received a lot of negative critical feedback from my associate and visiting lecturers which I had not anticipated or heard before. That affected my relationships with other teachers and my associate and my feelings of selfworth as a teacher. I felt as if I got a lot of judgement on my personal behaviours without anyone really getting to know me which was unfair"

Some students provided more detail of their experiences and included positive suggestions: "...I would rather have to hand in bits and pieces as I go so there are set assignments and deadlines rather than heaps over the entire period because sometimes I get lost in the assignment and I would rather get lost in the placement and make the most of the practical experience and knowledge of the other teachers..... Using assessments to plan experiences...can be quite overwhelming... I watch other teachers ... and that is a good way to learn about different opportunities but as part of the degree more situations and activities could be provided that we could brainstorm about to ensure we are going in well prepared..."

As students described their practicum challenges, they peppered their responses with emotive vocabulary referring to the feelings these challenges evoked to an extent not evident in other survey questions. For instance:

"Hard (to be motivated)", "exhausted", "(waiting for VL) very stressful... knocks my confidence down", "on edge", "overwhelming", "love and enjoy", "not sure", "struggle", "judgement unfair", "off side", "I want to throw in the towel... get over it".

Several entries referred to ethical dilemmas or professional behaviours which challenged student expectations, and a perception of contradictory feedback:

"I observed and questioned the ratio of teachers to children... I feel this put me off-side with some of the teachers... had to work even harder to gain their trust" 
"Building positive relationships with my associates which are open and reciprocal. Have found myself on multiple occasions to be out of the loop of how they felt I was doing"

"My VL seemed to not have been a teacher in a centre for years".

These entries provided additional student perspectives on the challenges of practicum and, while highly individualised, reveal students appeared to be most concerned with developing increasing confidence in their teaching behaviours and knowledge with the support of consistent and responsible feedback.

\section{Student emotions}

Participants were asked to indicate the frequency of a range of emotions they might experience on practicum (see Table 4.7). Ninety to $100 \%$ of students reported feeling energised and happy, satisfied, confident, and respected most of the time or often during their practicum. Students indicated they felt relaxed, supported and respected (80\%-85\%) often or most of the time. The emotions of feeling anxious, frustrated and cautious seemed to have mixed results. Over half the students (60\%-65\%) reported feeling cautious or anxious "most of the time" or "often". Unlike more positive emotions, a number of students reported they "never" felt anxious, cautious or frustrated.

In addition to signalling the frequency of emotions, students were also asked to enter examples for each emotion: "Please provide the first example that comes to mind for each emotion in each text box". (For example, Energised and happy when...., Anxious because....). Students provided a wide range of examples. The categories "Rarely" and "Never" provided possible insights into students' experiences as they frequently provided examples of their expectations of others as well as themselves. Students responded in a variety of ways that were at times ambiguous. For instance, a student identified she rarely felt anxious "because of assignments". Did this indicate that assignments were rarely the cause of anxiety or were assignments helpful in alleviating feelings of anxiety? Students also varied in whether they provided a negative or positive example to correspond with the frequency of the emotion they signalled which the researcher hadn't anticipated. 
Table 4.7 Student emotions on practicum

\begin{tabular}{|c|c|c|c|c|c|c|c|c|c|}
\hline \multirow[t]{2}{*}{ On practicum how often did you feel? } & \multicolumn{2}{|c|}{$\begin{array}{r}\text { Most of the } \\
\text { time }\end{array}$} & \multicolumn{2}{|c|}{ Often } & \multicolumn{2}{|c|}{ Rarely } & \multicolumn{2}{|c|}{ Never } & \multirow{2}{*}{$\begin{array}{r}\text { Total } \\
\#\end{array}$} \\
\hline & $\%$ & $\#$ & $\%$ & $\#$ & $\%$ & \# & $\%$ & $\#$ & \\
\hline Energised and happy & 60 & 12 & 30 & 6 & 10 & 2 & 0 & 0 & 20 \\
\hline Satisfied & 50 & 10 & 50 & 10 & 0 & 0 & 0 & 0 & 20 \\
\hline Confident & 35 & 7 & 65 & 13 & 0 & 0 & 0 & 0 & 20 \\
\hline Respected & 50 & 10 & 30 & 6 & 20 & 4 & 0 & 0 & 20 \\
\hline Relaxed / at ease & 25 & 5 & 60 & 12 & 15 & 3 & 0 & 0 & 20 \\
\hline $\begin{array}{r}\text { Supported/able to choose the direction of your } \\
\text { development }\end{array}$ & 15 & 3 & 70 & 14 & 15 & 3 & 0 & 0 & 20 \\
\hline Cautious & 25 & 5 & 40 & 8 & 30 & 6 & 5 & 1 & 20 \\
\hline Anxious & 20 & 4 & 40 & 8 & 35 & 7 & 5 & 1 & 20 \\
\hline Frustrated & 15 & 3 & 20 & 4 & 40 & 8 & 15 & 3 & 18 \\
\hline
\end{tabular}

Students' text entries indicated both their need for support, vulnerability to feedback (the push pull of wanting it yet not always liking it or accepting it), their perceptions of the centre climate and their feelings of competence. These entries also appeared to indicate students' expectations of other's roles as well as their own, particularly when it came to ideas of what a "good teacher" or good teaching is, for example:

"Children respect and listen to me"

"I can manage a group of children"

"I was building relationships with the children and their families"

Examples of student comments upon positive emotions associated with their practicum experience included their relationships and work with children, teachers and families, and the perceived centre climate and level of regard, support and feedback experienced by students. Student comments in relation to feeling energised and happy were characterised by relationship building and experiences with children, teachers and families in conjunction with students' perceived levels of support within the centre environment. Exceptions were two entries: "(When) I start the day" and "when arriving at the centre". Notably, many entries reflected students pleasure in being with the children, particularly while they were "happy", for instance:

- Most of the time, when "I am around the children and they are happy and enjoying what they are doing", "I see children learning", "children and I eat lunch" 
- Often, when "I feel supported by other teachers and am participating in a fun activity with the children", "ensuring I develop relationships with parents"

Students' feelings of Satisfaction during their practicum were largely attributed to their sense of working effectively with children, for example:

- Most of the time because: "strategies I was using worked with the children helping their emotional wellbeing", "I am able to have positive interactions with children and empower their learning and wellbeing"

- Often because: "when the day was over and I felt I had a successful day".

The satisfaction of completing assignments also featured in students' entries, for example "to get work done on time and well". One student included the satisfaction of being close to the end of their qualification: "this is my last year of study". Progress in achieving personal and professional goals was also mentioned by students, for instance: "I am achieving my goals" and "I am confident in mat times". A number of students attributed their satisfaction to feedback: "I had great discussions with my visiting lecturer or associate teacher", "I am being encouraged".

Students' comments on their feelings of confidence were linked to perceptions of the centre climate and quality of feedback they received. Students' feelings of efficacy working with the children, teachers and families as well as feelings of familiarity and support were common themes, for instance:

- Most of the time, when: "I could feel my assertiveness was making a difference and the children were listening to me", "I successfully help a child", "I receive positive feedback"

- Often, when: "facilitating group learning experiences", "Children listen to me and ask for my help", "I connect with family", "I am able to contribute what I am passionate about".

Students associated feeling respected with having their opinions, ideas and skills regarded by their Associate teacher, the teaching team and children's families, for example:

- Most of the time because: "the teachers ask for my opinion and encourage my contribution to the centre practices", "I am valued as a student teacher", "I am welcomed"

- Often because: "my ideas are valued", "I am viewed as part of the team", "the teachers ask me for help"

- Rarely because: "I am a teacher", "parents talk to me", "of my ideas". 
Comments made in relation to feeling Relaxed indicate that the perceived climate of the centre and levels of support offered to students had a substantial impact on their feelings of ease, for instance:

- Most of the time because "other teachers are supporting me" "I could see I was making a difference in the lives of these children" "I feel like I am not being judged"

- Often because "I get support from the teachers" "I've been told by my associate and visiting lecturers that I'm doing a good job", "I feel comfortable at the Centre"

- Rarely because "the other teachers were (not)".

In relation to student feelings of being Supported and able to choose the direction of their development, students identified their Associate and other teachers' trust in them and their willingness to support student initiatives as contributing to their sense of efficacy.

- Most of the time when: "my associate teacher supports and encourages me"

- Often when: "my AT and other teachers are willing to spend time helping me", "(I) wanted to try out a new idea", "my associate is backing me", "I am in control"

- Rarely when: "Associate teacher would sit down and discuss how I was going", "my associate trusted me".

More challenging emotions for students were characterised by their unmet expectations of their own and others professional behaviour. Comments in relation to feeling Cautious provided a wide range of responses. Students, whether identifying feeling cautious most of the time, often or rarely, provided examples related to their professional behaviour, for instance "observing children" and "talking to parents for the first time". Many examples reflected teaching challenges and indicated again students' sensitivity to the perceived climate of the centre and the levels of support they anticipated.

- Most of the time when: "arriving", "dealing with behavioural problems or issues around practice"

- Often when: "teaching team were stressed", "parents are observing", "dealing (with) the behaviour of children".

- Rarely when: "I am not accepted", "I don't know how to do something that is asked of me", "My associate was inconsistent with her approach. This made me weary at times and made me realise how important it is to document anything that could lead to potential conflict down the line".

Students' comments regarding feeling Anxious during practicum included recurring examples of unfamiliarity and unease in the Centre setting. Being in a new environment with a sense of not 
knowing how they were doing and being "watched" by other teachers also surfaced in these entries. Whether these examples indicate student levels of confidence and their perception of being trusted in their roles is not clear.

- Most of the time, because: "it's a new environment, children and teachers", "other staff are watching me"

- Often, because: "I didn't know if anyone liked me or thought I was a good teacher", "I am being watched constantly because I am a student", "I may not have the knowledge of how they do things"

- Rarely because: "Visiting Lecturer gave me feedback that was irrelevant and didn't actually make sense".

Students' comments in relation to the emotion Frustrated were characterised by apparently strongly held perspectives. Frustration at a perceived lack of regard by others was clear (whether VL, AT, or teachers). Students also reported feeling frustrated that their expectations of levels of support were not met and that they felt they were not listened to. Two students recognised the source of their frustration was directly attributable to their desire to respond effectively to children: "I wish I did something differently which could have provided more educational benefit to a child", "I don't know effective strategies for problem solving among children".

- Most of the time when: "not listened to by associate/other staff"

- Often when: "I was judged off of a brief moment of teaching in my visiting lecture report", "I am seen as just an extra pair of hands".

- Rarely when: "Associate teacher talked behind my back and blindsided me at visiting lecturer visit", "I could see at times there was no point in giving my actual opinion and recollection of events because it would have been dismissed"

Students' emotional responses as they built relationships within the centre and worked through their assignments and goals appear particularly affected by the support and feedback they perceive they were receiving with these being the most common examples reported by students across all emotions. The Centre climate and culture of responsiveness appears to be closely related to students' perception of their experience and their resulting emotional responses.

\section{Perceived source of feelings}

Students were also invited to comment upon what they felt had the biggest impact on their feelings during their practicum with the prompt "For instance, personal situation, mental health, work, study, 
professional philosophy, life, support". Of the 19 responses, students largely identified the support of their AT and teaching team as a contributing factor to their feelings:

"support from Associate teacher and the rest of the teaching team"

"Having a good close relationship with associate and having good communication as it was horrible thinking I might have done something wrong but your associate not talking to you".

Managing their personal situations including mental health, previous life and practicum experiences, personal attitudes and lifestyle also featured strongly:

"Both personal situation regarding mental health and previous negative experience on placements"

"Having a healthy stable lifestyle in conjunction to my personal philosophy keeps me feeling excited to work with young children".

Several students continued to report on events that did not meet their professional expectations and that they had described in responses to previous questions:

"Being spoken to in front of the children and teachers"

"Being mindful of the regulations in early childhood and being surprised that they are not always followed".

Students appear to attribute their emotions to the support they receive within the Centre throughout their practicum and their ability to juggle the demands of their life experiences and situations.

\section{Associate teacher and Visiting lecturer assessment}

The next section of questions sought student perceptions on their relationship with and support from their Associate teacher and Visiting lecturer(s). Two students who didn't respond to this question had completed the post-practicum survey, leaving a maximum of 18 students responding.

\section{Associate teacher assistance}

Students generally found Associate teachers encouraging, supportive and inclusive. Two-thirds $(66.7 \%)$ of students responding to this question rated "Acknowledgement and support" by their Associate as "extremely helpful". The offering of "advice and guidance that developed my teaching" provided a noticeable contrast in responses with 11 students (61.1\%) rating this as "extremely helpful" compared with four students (22.2\%) who rated it "not at all helpful". Students also appear evenly split between reporting "extremely helpful" and "helpful" in their experiences of their Associate teacher's discussion of ideas and observations, written reports and modelling of practices. 
This suggests that these behaviours to support student development may not be being undertaken or utilised by Associate teachers as effectively as they might be. A total of six students (33\%) rated different aspects of their Associate teacher experiences "not at all helpful".

The category of "other" provided four text entries. The entry rated "not at all helpful" related to "Providing feedback" by a student who had also rated all other aspects of her Associate teacher as not at all helpful with the exception of including her in the teaching team. The remaining three text entries rated "extremely helpful" indicate further aspects of Associate teacher support highly valued by these students':

"Letting me experiment with my own activities with children"

"Modelled leadership skills"

"Helping me to know how I could help them".

Students appeared generally satisfied with their Associate teacher's assistance. However, students appear mixed in their views of their Associate teacher's practices guiding, modelling, discussing and recording students' teaching and learning.

Table 4.8 Associate Teacher Assistance

\begin{tabular}{|r|r|r|r|r|r|r|r|}
\hline \multirow{2}{*}{ How helpful was your Associate Teacher in your teaching } & \multicolumn{2}{|r|}{$\begin{array}{r}\text { Extremely } \\
\text { helpful }\end{array}$} & \multicolumn{2}{|r|}{ Helpful } & \multicolumn{2}{|r|}{$\begin{array}{r}\text { Not at all } \\
\text { helpful }\end{array}$} & Total \\
\cline { 2 - 9 } & $\%$ & $\#$ & $\%$ & $\#$ & $\%$ & $\#$ & $\#$ \\
\hline Acknowledgment and support & 66.7 & 12 & 22.2 & 4 & 11.1 & 2 & 18 \\
\hline Encouragement & 61.1 & 11 & 33.3 & 6 & 5.6 & 1 & 18 \\
\hline Included me in all aspects of the teaching team & 61.1 & 11 & 27.8 & 5 & 11.1 & 2 & 18 \\
\hline Offered advice and guidance that developed my teaching & 61.1 & 11 & 16.7 & 3 & 22.2 & 4 & 18 \\
\hline Modelling of inspiring/achievable practices & 50.0 & 9 & 38.9 & 7 & 11.1 & 2 & 18 \\
\hline Discussion of my ideas and observations & 44.4 & 8 & 44.4 & 8 & 11.1 & 2 & 18 \\
\hline Written reports & 44.4 & 8 & 44.4 & 8 & 11.1 & 2 & 18 \\
\hline Other (please describe) & 16.7 & 3 & 0.0 & 0 & 5.6 & 1 & 4 \\
\hline
\end{tabular}

Students were asked to comment further on the assistance they received from their Associate. Seven out of the nine respondents to this question were positive and appreciative of their Associate teacher's help, for example:

"Immense support and positive reinforcement throughout the entire time".

"I felt like I was truly a part of the centre life". 
However, six students also expressed their disappointment about aspects of their experiences with their Associate teachers and explained their views, including:

"I think the relationship with your associate is the most important and when that breaks down it impacts whether you want to be there. My Associate often said she would do things and not follow through and went through phases of not talking to me which creates a lot of self doubt" "I was a bit disappointed at my final report from my associate teacher. Even though she passed me on all teaching standards, I felt that her comments were generic and there wasn't really any meaning behind them. ...This annoyed me a bit, but the visiting lecturer reports were very detailed and this made me very happy".

Several students expressed empathy for the Associate teacher and an acknowledgment of possible constraints and demands of the AT's roles, for example:

"Great teacher and kind supportive person but the environment did not allow for her to showcase these traits"

"Although I felt that my AT was extremely supportive and helpful to me, I did often feel that she did not have so much time to meet with me formally during the week as she did not have time allocated specifically for me and for her work as an AT. She either had to use her noncontact time that she was usually busy doing other important things with or read through my assignments etc after work hours. I also didn't get a mid-way report which would have been helpful for me".

One entry referred to the wider Centre team indicating the student's sensitivity to each teachers apparent responsiveness and her "acceptance" within the Centre environment:

"I found my associate to be wonderful but the rest of the teaching team took 4 weeks to really accept me into their centre. The other amazing person was the manager who had faith in my abilities. It was disheartening to not feel accepted by the entirety of the staff".

One student, whilst she had consistently rated her Associate teacher and the Centre highly throughout the survey, also recommended:

"In order for associate teachers to support a student I believe they need to attend a lecture where they have a general understanding of the assignments and work required". 


\section{Associate teacher feedback}

Students' perceptions of the feedback that they received from their Associate teacher were largely positive (see Table 4.9). Students indicated their Associate teacher's feedback was fair, constructive and assisted their learning. While they did not perceive they received feedback frequently from their Associate teacher, the feedback students did receive occurred most often as they worked with children and in formal meetings. Students acknowledged they also received useful feedback from the wider teaching team and that their Associate teacher utilised other teachers' perspectives in their feedback.

Table 4.9 Associate teacher feedback (18 respondents)

\begin{tabular}{|r|r|r|}
\hline Tick all statements that apply & $\%$ & Count \\
\hline I felt my Associate's feedback assisted my learning & 66.7 & 12 \\
\hline I felt my Associate's feedback was fair and constructive & 61.1 & 11 \\
\hline I received Associate feedback as I worked (gesture, facial expression, comments, & 55.6 & 10 \\
\hline Other members of the teaching team gave me useful feedback & 55.6 & 10 \\
\hline I received Associate feedback in formal meetings & 50.0 & 9 \\
\hline I felt my Associate's feedback included other teachers' views of my work & 50.0 & 9 \\
\hline I received Associate feedback frequently & 33.3 & 6 \\
\hline I preferred feedback from other members of the teaching team & 27.8 & 5 \\
\hline I received Associate feedback during breaks & 11.1 & 2 \\
\hline I felt my Associate's feedback hindered my learning & 11.1 & 2 \\
\hline
\end{tabular}

Students were also asked for further comments on their Associate teachers' feedback. Nine students provided responses. Students commented on their appreciation of feedback from the larger teaching team, for instance: "I really enjoyed recovering (sic) feedback from other members of the team as it was encouraging, supportive and reinforcing". Four students expressed disappointment with their Associate, noting they either didn't have meetings for feedback that were scheduled, they felt they didn't receive any feedback, they didn't feel respected and included or they felt more connected to the other teachers. Five students noted that their Associates' feedback was either only in formal meetings or that they wanted higher quality feedback from their Associate, for instance:

"I often felt like I wanted more constructive feedback, pointers and tips on how to do something better, and more explanations of what she was doing or how she handled a situation would be helpful (in the moment type discussions and reflections)" 
Three students made detailed recommendations explaining their experience with a degree of sensitivity for how these experiences may have arisen, for example:

"I felt as though my associate treated me being her student very formally and was hesitant to give me feedback. I rarely got positive feedback on the floor (actually cannot remember getting any) and when I would mention things I had done she hadn't noticed so couldn't comment. I got some positive feedback in meetings but mainly on my written work which made me feel like either I was terrible on the floor or she wasn't seeing me..."

Students who chose to add additional information about their Associate teachers' feedback acknowledged both their Associate teacher and the wider teaching team's feedback. Some students expressed disappointment with their AT, especially around meetings for feedback and the quality of AT feedback while some students acknowledged the workload demands and responsibilities of ATs.

\section{Associate teacher communication and relationship}

Students were asked to rate their perceptions of their relationship and communication with their Associate teacher (see Table 4.10). This had a smaller response rate $(\mathrm{N}=12)$. Results appear mixed. While students indicated they felt respect and regard "with" their Associate it is unclear whether this was the students' respect and regard for their Associate or whether they felt respected and regarded by their Associate.

Students appear to feel trusted, welcomed, and well informed about centre culture and practices by Associates. While students largely reported they were responsive in their communications, one student acknowledged that she was not. Students' perceptions of alignment with their Associate teacher's professional practices were mixed as was their perception of their Associate's interest in them beyond their practicum experience. Students appear to recognise that Associate teachers may not have as much time for them as they might wish. 
Table 4.10 Associate teacher communication and relationship

\begin{tabular}{|c|c|c|c|c|c|c|c|}
\hline \multirow[t]{2}{*}{ To what degree do you agree with the following? } & \multicolumn{2}{|c|}{$\begin{array}{r}\text { Absolutely } \\
\text { agree }\end{array}$} & \multicolumn{2}{|c|}{$\begin{array}{r}\text { Somewhat } \\
\text { agree }\end{array}$} & \multicolumn{2}{|c|}{$\begin{array}{l}\text { Don't } \\
\text { agree }\end{array}$} & \multirow{2}{*}{\begin{tabular}{|r} 
Total \\
$\#$
\end{tabular}} \\
\hline & $\%$ & \# & $\%$ & \# & $\%$ & \# & \\
\hline I felt respect and regard with my Associate & 83.3 & 10 & 16.7 & 2 & 0.0 & 0 & 12 \\
\hline $\begin{array}{r}\text { I was given responsibility and trusted in my student } \\
\text { teacher roles }\end{array}$ & 83.3 & 10 & 16.7 & 2 & 0.0 & 0 & 12 \\
\hline My Associate was welcoming and inclusive & 83.3 & 10 & 16.7 & 2 & 0.0 & 0 & 12 \\
\hline $\begin{array}{r}\text { My Associate shared information about the Centre's } \\
\text { beliefs, practices etc with me }\end{array}$ & 75.0 & 9 & 25.0 & 3 & 0.0 & 0 & 12 \\
\hline $\begin{array}{r}\text { Communication with my Associate was relaxed and } \\
\text { helpful }\end{array}$ & 66.7 & 8 & 33.3 & 4 & 0.0 & 0 & 12 \\
\hline $\begin{array}{r}\text { I was responsive in my communications with my } \\
\text { Associate }\end{array}$ & 75.0 & 9 & 16.7 & 2 & 8.3 & 1 & 12 \\
\hline $\begin{array}{r}\text { We had similar ideas about teaching style, best } \\
\text { practice and guiding children's behaviour }\end{array}$ & 41.7 & 5 & 41.7 & 5 & 16.7 & 2 & 12 \\
\hline $\begin{array}{r}\text { I felt my Associate showed a personal interest in me as } \\
\text { well as my teaching }\end{array}$ & 50.0 & 6 & 25.0 & 3 & 25.0 & 3 & 12 \\
\hline My Associate seemed to have little time for me & 8.3 & 1 & 41.7 & 5 & 50.0 & 6 & 12 \\
\hline
\end{tabular}

\section{Visiting lecturers}

Participants were asked to report on aspects of their Visiting lecturer assessment experiences (see Table 4.11). Students appear satisfied that discussions with Visiting lecturers were useful to their teaching development and that students contributed to these discussions, referencing their own understandings of pedagogy. While half of the students $(\mathrm{N}=9)$ found the observation stressful, they acknowledged that the discussion was useful to them. Just over half of students (55.6\%) found the Visiting lecturer report a satisfactory summary of their visit. Around one-third of students reported they found the Visiting lecturer discussion testing $(N=4 ; 33.3 \%)$ and confusing $(N=5 ; 27.8 \%)$. Two students (11.1\%) reported they were there to listen, get through the process and move on. These results appear to signal that Visiting lecturers could do more to assist students, particularly in the areas of building a climate of respect and ease in discussion of ideas (rather than "testing" student 
knowledge) and in clarifying feedback both directly with students and in the written summary of the visit.

Table 4.11 Visiting Lecturer process of assessment (18 respondents)

\begin{tabular}{|c|c|c|}
\hline Tick all that apply & $\%$ & Count \\
\hline $\begin{array}{r}\text { I was able to contribute to my Visiting Lecturer's assessment by discussing my } \\
\text { teaching decisions and approach to teaching }\end{array}$ & 84.0 & 15 \\
\hline $\begin{array}{r}\text { I found the Visiting Lecturer discussion useful for next steps/strategies to } \\
\text { develop my practices }\end{array}$ & 72.3 & 13 \\
\hline $\begin{array}{r}\text { I found the Visiting Lecturer report summarised what was observed and } \\
\text { discussed }\end{array}$ & 55.6 & 10 \\
\hline $\begin{array}{r}\text { I found the Visiting Lecturer observation stressful but useful in professional } \\
\text { discussion }\end{array}$ & 50.0 & 9 \\
\hline The Visiting Lecturer professional discussion felt like a test & 33.3 & 6 \\
\hline I was confused by the Visiting Lecturer's feedback in the professional discussion & 27.8 & 5 \\
\hline $\begin{array}{r}\text { I don't say much during the Visiting Lecturer discussion, I'm there to listen to the } \\
\qquad \text { Visiting Lecturer's views }\end{array}$ & 11.1 & 2 \\
\hline I get through the Visiting Lecturer assessment visit, then forget about it & 11.1 & 2 \\
\hline
\end{tabular}

Students were invited to provide further comments on their experiences with Visiting lecturers' and eleven students contributed entries. Students were largely appreciative of their Visiting lecturers' observation and engagement with them during professional discussions which provided feedback and ample opportunities to reflect and explore views, for example:

"I felt I had really good visits this practicum as the visiting lecturers both took a lot of time to observe me and then gave me a lot of time and opportunity to discuss what I thought and shared my ideas and reflections as well. I found this to be extremely helpful in my reflections about my teaching and hope that my next practicum visits will be similar!"

Students commented on the Visiting lecturers' manner and the practices which helped them to feel at ease, for instance: 
"... the visiting lecturers were both very friendly and had casual conversations with the other staff and interacted with children as initiated by the child. They sometimes even conversed with me during the observation."

One student appeared to differentiate between "conversation" and "testing" in her discussions attributing this to the degree of familiarity or unfamiliarity with her Visiting lecturer. She appears to imply that conversational discussion with a familiar VL, helped her to participate and the more she can contribute the more valuable it was to her.

"Some visiting lecturers test you in the discussion and some have a conversation. I think that your relationship with the lecturer helps the lecturer understand you and have a better knowledge of your thinking, where lecturers that didn't know me tested me more. I also found the more that you can talk about what you have learnt, challenges and successes help in the discussion".

Six students commented on Issues of perceived "inconsistency" across Visiting lecturers' expectations and approaches, for example: "I felt the grades and comments were conflicting of one another. Also, that each of the three which I had, had different outlooks and expectations of me, making the process confusing and challenging". Students reported not being observed teaching or not being observed for an adequate period:

"My first visiting lecturer did not actually observe me - it was as though she just did not have the time to do it and couldn't be bothered. She talked to my associate teacher and to me and then left and I did not feel benefitted at all".

"They did not observe me well enough. I thought they spent more time talking to the other teaching team than observing how I am as a teacher"

One student appeared to question the relevance of her Visiting lecturer's guidance, recommending recent teaching experience:

"I think it would be awesome if a visiting lecturer had been teaching within a year of their visit so they understand how things are done in this day and age"

These entries suggest that ITE programmes could do more work to ensure the consistency of approach of VLs, particularly in the areas of agreed understandings of assessment criteria and the tone of discussion, support and guidance which further enables students' agency in their teacher development and practicum assessment. 


\section{Video Review (VR)}

Students were asked to indicate their prior experience of using VR in their teaching training. Over half of the students responded that they had no experience of viewing themselves working with children. Fewer than half of respondents had experienced video as a tool for their reflection upon their teaching during their ITE programme.

Respondents were asked to rate the perceived or anticipated challenges of VR (Table 4.12). Sixteen students reported the most challenging aspects of VR lay in sharing their practices with others $(57.9 \%$ very challenging, $26 \%$ mildly challenging). Feeling authentic while being videoed was reported as challenging by 15 students (78.9\%), and confronting images of themselves was challenging for $73 \%$ $(\mathrm{N}=14)$.

For $63 \%$ of students, developing strategies to strengthen their teaching was reported as a challenge. For twelve students (63\%), their ability to recognise what they did well was more challenging than recognising what they could improve (57.9\% not at all challenging). Students reported that VR to develop their teaching further $(\mathrm{N}=12)$ and to reflect upon their teaching practices $(\mathrm{N}=11)$ as "mildly" to "not at all challenging". One of the least challenging aspects of video review for students was gaining consent for filming.

Significant challenges perceived by students using VR appear to be focussed on the de-privatisation of their practices, feeling authentic as they are filmed and confronting images of themselves. While recognising what they do well in their teaching and developing strategies to strengthen their teaching appear to be secondary concerns, they are still reported as challenging. Least challenging for students was reported as "recognising what I could improve". 
Table 4.12 Perceived challenges of video

\begin{tabular}{|c|c|c|c|c|c|c|c|}
\hline \multirow{2}{*}{$\begin{array}{l}\text { How challenging did you find/would you anticipate the } \\
\text { following? }\end{array}$} & \multicolumn{2}{|c|}{$\begin{array}{r}\text { Very } \\
\text { challenging }\end{array}$} & \multicolumn{2}{|c|}{$\begin{array}{r}\text { Mildly } \\
\text { challenging }\end{array}$} & \multicolumn{2}{|c|}{$\begin{array}{l}\text { Not at all } \\
\text { challenging }\end{array}$} & \multirow[t]{2}{*}{ Total } \\
\hline & $\%$ & $\#$ & $\%$ & \# & $\%$ & \# & \\
\hline Sharing my video with others & 57.9 & 11 & 26.3 & 5 & 15.8 & 3 & 19 \\
\hline Seeing/hearing myself & 36.8 & 7 & 42.1 & 8 & 21.1 & 4 & 19 \\
\hline Being filmed/being my 'usual' teaching self & 47.4 & 9 & 26.3 & 5 & 26.3 & 5 & 19 \\
\hline Recognising what I did well & 26.3 & 5 & 36.8 & 7 & 36.8 & 7 & 19 \\
\hline $\begin{array}{r}\text { Developing "next steps" / strategies to strengthen my } \\
\text { teaching }\end{array}$ & 15.8 & 3 & 47.4 & 9 & 36.8 & 7 & 19 \\
\hline Reflecting on my teaching practices & 15.8 & 3 & 42.1 & 8 & 42.1 & 8 & 19 \\
\hline Planning for filming & 10.5 & 2 & 47.4 & 9 & 42.1 & 8 & 19 \\
\hline Gaining consent & 5.3 & 1 & 42.1 & 8 & 52.6 & 10 & 19 \\
\hline Recognising what I could improve & 5.3 & 1 & 36.8 & 7 & 57.9 & 11 & 19 \\
\hline
\end{tabular}

When asked to rate aspects of VR (see Table 4.13), students provided mixed results. Students appear somewhat ambivalent about the usefulness of VR in their discussions with their ATs and VLs (23.5\% absolutely agree, $64 \%$ somewhat agree). However, fourteen students primarily agreed that VR would be useful to gain further perspectives of their practices as others see them ( $47.1 \%$ absolutely agree, $35.3 \%$ somewhat agree) and that they saw the value of using VR (11.8\% absolutely agree, $52.9 \%$ somewhat agree). These results may signal STs may be anticipating how VR might be utilised in discussion with AT's and VL's and whether it would be used to assess rather than support their teaching development.

Nine students (53\%) indicate their reluctance to share video for reflection, preferring to use this as a tool for reflection on their own while twelve students (70.6\%) acknowledged they may have found VR disconcerting but were able to overcome these feelings. While $52.9 \%$ of students didn't agree at all that VR was something they wanted to avoid, a significant number of students chose not to respond this statement. 
Table 4.13 Student responses to video review (17 respondents)

\begin{tabular}{|c|c|c|c|c|c|c|c|}
\hline \multirow[t]{2}{*}{ To what degree do you agree with the following? } & \multicolumn{2}{|c|}{ Absolutely agree } & \multicolumn{2}{|c|}{$\begin{array}{r}\text { Somewhat } \\
\text { agree }\end{array}$} & \multicolumn{2}{|c|}{$\begin{array}{r}\text { Don't } \\
\text { agree at } \\
\text { all }\end{array}$} & \multirow{2}{*}{$\begin{array}{r}\text { Total } \\
\#\end{array}$} \\
\hline & $\%$ & \# & $\%$ & \# & $\%$ & \# & \\
\hline $\begin{array}{l}\text { Video review would be useful in my discussions with } \\
\text { my Associate and/or the Visiting Lecturer }\end{array}$ & 23.5 & 4 & 64.7 & 11 & 11.8 & 2 & 17 \\
\hline $\begin{array}{r}\text { Video review helps me to see my practices as others } \\
\text { see them }\end{array}$ & 47.1 & 8 & 35.3 & 6 & 5.9 & 1 & 15 \\
\hline $\begin{array}{l}\text { Video review is something that I want to continue } \\
\text { because I see its value in my teaching development }\end{array}$ & 11.8 & 2 & 52.9 & 9 & 23.5 & 4 & 15 \\
\hline Video review is best left for me to reflect upon alone & 17.7 & 3 & 35.3 & 6 & 35.3 & 6 & 15 \\
\hline Video review was disconcerting, but I got used to it & 17.7 & 3 & 52.9 & 9 & 5.9 & 1 & 13 \\
\hline Video review is something that I want to avoid & 11.8 & 2 & 11.8 & 2 & 52.9 & 9 & 13 \\
\hline
\end{tabular}

Students seem to acknowledge VR could be helpful to see their practices as others see them and helpful in practicum discussion yet on the other hand they appear to not want to share their video, preferring to reflect on their practices alone. They want to use VR but don't want to share it and seem inclined to avoiding its use if possible. The confronting nature of both seeing and hearing themselves and sharing these images appears to concern students more than the possible value to the development of their teaching.

Table 4.14 Willingness to use video voluntarily

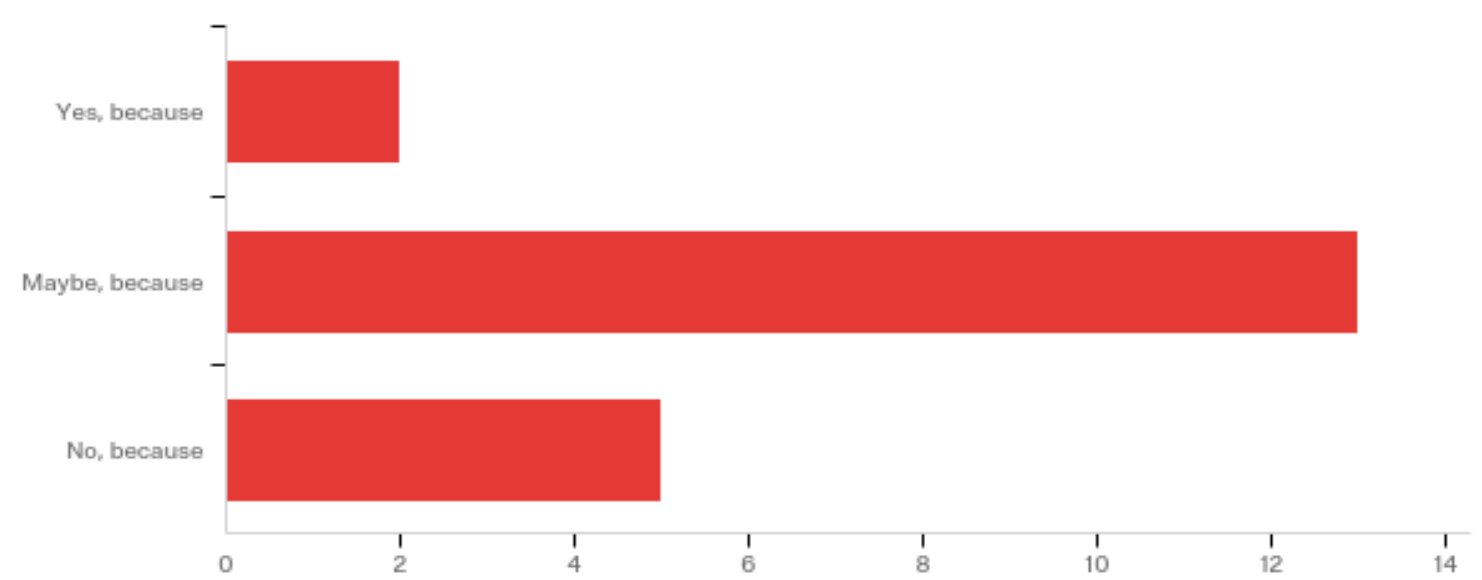


When asked to indicate whether they were willing to use VR voluntarily (see Table 4.14) students indicated their ambivalence (65\% Maybe). However, their comments were positive as they acknowledged the potential benefits to their teaching.

"I do think it would be helpful to know what I do well and see it actually happening" "It may help me to see personally where I can improve on and what I'm doing well as opposed to just hearing it from my associate or visiting lecturer"

Students' frequently prefaced their comments with expressions of discomfort, for instance:

"It's out of my comfort zone, but it's also good reflection"

"I would be very nervous, but I believe it could be beneficial".

Students seem to relate the usefulness of the VR process as contingent upon their level of familiarity with the centre and control over the context in which the video was recorded.

"Depending on what area I would be recorded in as I feel being record doing something I am uncomfortable in wouldn't show an accurate representation of my teaching" "It depends if I felt 100\% comfortable with the children, teachers, and whanau"

Several students noted their discomfort with de-privatisation of their practice, for example:

"It would be good for a personal level to be able to see yourself but I would hate for others to judge me based on the video like visiting lecturers"

While also noting that it may be more beneficial to share their video:

"I would rather not view it with anyone but myself but if I didn't get feedback from anyone else than I wouldn't find it as helpful".

Two students who responded "Yes" they would volunteer to use VR, anticipated the benefits of viewing their practices for reflection and to clarify perspectives in professional discussion:

"You can look back at what your teaching practise looks like".

"I think it would be really useful to see how what I think I do might differ and may be what others see. Or maybe our different perceptions of the same thing could explain why some discussions are a bit confusing".

Of the five students who reported they wouldn't voluntarily use video, only three provided comments:

"I'm not entirely comfortable with the idea". 
"It probably wouldn't have crossed my mind to do this on practicum unless it was a requirement for an assignment until thinking about it while doing this survey" "I hate seeing myself on film and I don't feel it would be helpful"

However, when students were asked to comment on whether they felt VR review might have assisted them in their discussions with their Associate teacher and Visiting lecturer, two thirds of respondents entered "Yes" ( $N=10)$. Students continued to comment on the benefits of seeing their practices and discussing perspectives, for instance:

"Yes, because it would allow for the student, visiting lecturer, and associate teacher to see the student teacher's teaching in practice rather than simply describing it. This puts a physical action to just word description. I also would think no, because it may bring added pressure and stress to the student"

Other students recognised the potential value of video as a tool to argue their own viewpoints in professional discussions, for example:

"Yes, because I think there were some things which I would like to have disputed but didn't feel I could back up".

One student saw video as a means to better understand the verbal feedback she received on practicum:

"Yes. I feel as though it was hard being told that you do something, but you don't notice you do or know what it looks like so how can you agree when you feel as if you acted differently. It would be easier to explain why I did what I did, it would also make it easier to see what you did that you could have improved on".

Four students answered "maybe" with several referring to their feelings of discomfort while others acknowledged the benefits of VR.

"Maybe however it would also feel more like a test which would be added stress"

"Possibly, to help to pinpoint specific details of what occurred rather than anecdotal recollections from both sides (as I found there was so much going on during the visiting lecturer's observation that I forgot a lot of what was said or done at the time). It may be good to see my teaching practice and have it recorded in this way". 
One student responded with "No, I was fine when talking to my Associate Teacher and Visiting Lecturer".

Students appear to recognise that VR could be beneficial to their teaching development during practicum in numerous ways: seeing their practice as others do; data to reference in professional discussions; and to explore perspectives. Their primary concerns seem to be in their vulnerability to judgment and the additional stress anticipated in filming and seeing themselves at work with children.

This chapter has presented the results of the five areas of survey content: participant demographics; perceived significance of practicum, goals and challenges; student emotions on practicum; associate teacher and visiting lecturer assistance and feedback; and, perception of video as a tool on practicum. These results will be discussed in the next chapter. 


\section{Chapter 5: Discussion}

The research questions for this study are: "what are ECE student teachers' perceptions of the significance and challenges of their practicum experiences" and "what are ECE student teachers' views about the potential inclusion of video review within the practicum?".

This chapter discusses the findings concerning STs' perceptions and experiences of practicum. Challenges identified by STs in this study included developing practical skills, confidence, and relationships as well as challenges faced within the assessment process. ST perceptions of these experiences appear to be influenced by their beliefs, agency and emotions which are also discussed. STs' views on the potential challenges and benefits of VR use during practicum are also explored. Finally, implications for further research and the limitations of the current study are identified.

\section{Practical skills and confidence: emotion and agency}

Opportunities to develop confidence in a wide range of practical skills and developing understandings was reported as a challenge by STs in this study. Developing confidence was influenced by the perceived relational climate and subsequent STs' judgements of the opportunities afforded for support and feedback from ATs, VLs and the wider teaching team. This finding aligns with previous international and New Zealand research (e.g., Caires et al., 2012; Loizou, 2011; Murphy \& Butcher, 2013; Turnbull, 2005). This initial ST perception of centre climate and sense of the culture of responsiveness appears to affect ST agency, emotions, their perceptions of experience and subsequent confidence. STs consistently described the most challenging aspects of practicum lay within perceived levels of support and feedback to develop their confidence. References to support and feedback were also consistently evident in the examples STs gave of situations where they experienced different emotions. These findings appear to align with Van Schagen Johnson et al.'s (2017) findings that ST satisfaction, efficacy, feelings and 'fit' with AT's are inter-related during practicum.

STs reported they were 'happy and energised' most of the time. While Van Schagen Johnson et al. also found STs on average felt energised and relaxed, they argued that feeling relaxed was ambiguous, suggesting that this may have been indicative of STs' lack of engagement. In contrast, while this study also found STs reported being 'relaxed and at ease', these feelings were indicative of ST agency and confidence in the practicum setting. STs also reported feelings of 'satisfaction', 'confidence', 'respect' and 'support in pursuing the direction of their development' which also appeared to align with their sense of agency. However, these feelings also appear contingent on the perceived climate of trust and responsiveness afforded by AT's, experienced within the teaching team with children and their families. STs appear sensitive to and discerning of the relational climate and 
whether it affords them opportunities for their teaching growth (Murphy \& Butcher, 2013). Loizou (2011) found STs' filtered feedback, setting their own agenda when they perceived mentors didn't meet their expectations of support and there were examples of this in the results of this study. The perceived centre climate appears to be crucial to ST's feelings, perceptions and resulting adaptability, paralleling Caires et al.'s (2012) finding that ST adaptability in one domain was highly related to adaptability in all others. Centre climate has also been related to ST's levels of satisfaction as highly predictive of efficacy (Van Schagen Johnson et al., 2017) and ST expectations of mentoring behaviours which align with STs (Loizou, 2011).

Students provided rich and candid descriptions of their emotions in this study (see text entries following Table 4.8). These appear to reflect perceptions of acceptable as well as uncomfortable emotions in teachers. Madrid et al. (2013) suggested emotions define how and what one chooses to see or not see and as such are tied to professional beliefs and identity. STs rarely or never reported feeling cautious, anxious and frustrated, and frustration was most adamantly reported as "never" (see Table 4.8). The text entries where STs described less comfortable emotions included examples of appropriate professional forethought; for instance, approaching parents for the first time or guiding children's behaviour. These indicate some STs may have recognised less comfortable emotions as cues to pause, thus creating a conscious space before responding. This self-reactiveness (Bandura, 2001) and self-awareness (Goleman, 1996) is critical to agency, reflection and self-regulation.

Positive emotions had a different emphasis with no STs reporting that they "never" experienced these during practicum. STs' beliefs about professionalism, how this is constructed within ITE and how emotions (other than 'caring') have been previously explored in the discourse of the professional ECE teacher (see, for example, Madrid et al., 2013; Osgood, 2010) could be usefully explored further by ITE providers. Madrid et al. have suggested "learning how to feel as an educator is part of the hidden curriculum in early education programs" (2013, p.275) and, "too little attention has been given to the complexity of how emotions, perspectives and practices provide productive grounds for struggle and growth in ECE" (2013, p. 289). The findings of this study indicate that ST emotions are a powerful contributor to the practicum experience, suggesting that while maintaining standards of professional behaviour is both ethical and desirable in ECE teachers, there may also be room to explore the possibilities of discomforting emotions with STs. Such emotions may act as cues to alternative productive behaviours that both acknowledge, model and exemplify emotional self-awareness and promote self-regulation in interactions with children, ATs and VLS.

STs' feelings of being authentically welcomed and valued as they begin practicum strongly influence their sense of belonging and whether they perceived the centre climate offers them support and 
feedback. STs provide repeated examples of the challenges they encountered during practicum in relation to their feelings of being included and well-regarded within their relationships with children, teachers and ATs. It is possible that STs may be responding to the climate of 'relational trust' (Bryk \& Schneider, 2003) evident to them in their AT and the wider teaching team's practices. This finding adds to the previous research by Loizou (2011), Murphy \& Butcher (2013) and Turnbull (2005) who each found the warmth of welcome perceived is highly influential for STs' practicum experience as it relates to ST relationships and subsequent feedback and support.

While effective relationships with children, supervisors, peers and other teachers may indicate the relative confidence, self-awareness and social skills of STs, the impact of STs' emotions and subsequent satisfaction during practicum builds potential for mastery experiences and STs' strengthening agency. Van Schagen Johnson et al. (2017) found feelings and 'fit' (alignment of ST-ATs) influenced satisfaction and efficacy while STs' capacity to adapt to the challenges they encountered during practicum were linked by Fives et al. (2007) to increasing efficacy and decreased burnout symptoms. Given the impact of STs' emotions evident in this study, there are implications for how New Zealand ITE providers and EC services strengthen practices that reduce STs' vulnerability and stress.

\section{Practicum goals: agency and reflection}

Bandura (2001) asserted one's agency is evident within one's beliefs, perceptions of challenge and goals. In turn these highly influence motivation, and thus the level of effort expended and degree of persistence shown. The practicum goals reported by STs were mainly general and personal goals, indicative of ST beliefs about perceived gaps in their knowledge and skills within the 'real' teaching context of practicum. Developing confidence was often reported by STs as both a challenge and a goal and hence the pursuit of confidence appears to drive STs' motivation (see Dweck, 2000). The goal of 'confidence' and the challenges reported in its achievement give rise to whether STs recognise their agency and how they might enact their agency within the practicum. This in turn suggests potential for ITE programmes to further foreground ST agency and to consider how they may provide greater support to students to become more agentic.

STs' text entries about their goals indicated a shift from thinking and talking about teaching to doing teaching. Or, as Gibbons et al. (2018, p.47) suggest, during practicum ST's experience the "perceived divisions of knowledge/theory and practice as the 'talk of quality' and the 'doing of quality' in terms of their development of an identity as teachers". This may provide one explanation for STs' apparent confusion about the significance of, and self-responsibility for developing and working towards professional goals. Such tensions raise questions about how ITE programmes emphasise ST goals 
within the theory-practice interface and the extent to which ST goals are tracked to support their developing agency throughout their teacher education. The challenges STs perceive and the primarily personal and general development goals they set may be indicative of their short-term aspirations and narrow focus for their practicum.

The practicum goals described by STs suggest that these were not consistently viewed as the fundamental basis for developing agency, engaging in reflection and their ongoing teacher development. The generality of their goals suggests STs may have difficulty developing worthwhile goals or may not take the process of goal setting seriously. The finding that STs seldom developed strategies to achieve their goals or revisited the relevance of their goals, and often maintained the same goals from one practicum to the next indicates that STs have either a limited understanding of the purpose of or don't see the relevance of setting goals within their teaching development. Some STs' superficial engagement with their goals may perhaps be indicative of their underlying beliefs regarding agency and their subsequent levels of persistence and effort in actualising teaching goals, given Dweck's (2000) argument that one's orientation to performance or learning achievement goals may influence motivation and subsequent effort and persistence in the face of challenge. Bandura (2001) maintained goals are critical to agency as they inherently require intentionality, forethought, self-reactiveness and self-reflectiveness. This may give rise to investigate further how STs undertake reflection upon their goals.

Several survey questions in this study explored STs' perceptions of the significance of and challenges in engaging in reflection within the practicum. Students indicated that their practicum goals offered frequent and easy opportunities for reflection, suggesting that STs may interpret reflection as 'give thought to', or 'remember' rather than as a critical and systematic exploration of beliefs, assumptions, alternative perspectives and possibilities. Bayat (2010) and Sumsion (2000) also found ST reflection problematic during their teacher education. Factors inhibiting reflection have been attributed to STs' attitudes towards learning, teaching, knowledge and support (Sumsion, 2000) and ITE programmes may need to examine the ways in which they assist STs to develop reflective practices (Bayat, 2010, Sumsion, 2000). Reflection on practice was reported by STs in this study as both a significant aspect of practicum, that was undertaken regularly, and was not at all challenging. Bayat (2010) also reported STs' perceptions that their reflection was nothing new to them. STs engaged in professional reflection appear challenged to find ways to reflect that have productive professional meaning (Bayat, 2010; Atiles \& Pinholster, 2013). While some STs indicated that they found discussion with their VLs 'testing' in the current study, it could be STs were responding to VLs asking them to reflect critically upon their beliefs and practices in ways unfamiliar to STs (see Bayat, 2010). 
Perhaps this taken for granted attitude by STs towards undertaking reflection and developing professional goals may reflect STs' perceptions of these skills as 'tasks required' rather than effortful essential tools to assist their on-going teacher development. When ST goals are developed through intensive self-reflection and critical inquiry, the meaning within their purpose and resultant confidence in developing practices becomes evident (Atiles \& Pinholster, 2013; Stephenson, 2006). Shifting responsibility and power to STs may be a key to not only developing ST attunement to agency but also to developing intrinsic motivation, interest and development of reflective practice (Stephenson, 2006). Smith (2016) suggests a practicum-based teacher education where teacher educators build their courses in response to STs' practicum experiences and inquiry rather than predeciding the practicum outcomes. Such an approach may enable further ITE programme responsiveness and exemplify the nature of teaching/learning as related to children (see Stephenson, 2006) that ITE providers may model.

While STs' reported challenges and goals that appeared highly individualised, these were largely concerned with developing their confidence. This may be indicative of a focus by STs on performance rather than learning goals (Dweck, 2000). Bandura (2001) suggested agency and efficacy are related to future-oriented goals yet general goals with few measures may be too indefinite and noncommitive to motivate one's persistence. Bandura also asserted that efficacy is most influenced by mastery experiences which are only achieved over time, with effort, self-responsibility and risk. He posed people are not always inclined to this work in achieving mastery. While STs indicated their longer-term goals such as completing their qualification, finishing assignments, or passing the practicum assessment, few STs have developed their goals to include strategies - in the case of confidence, what might confidence would look (see discussion on video below) or feel like (Ord \& Nuttall, 2016). STs reported they often continued with the same goals from one practicum to the next, possibly indicating they either have little structure to support them to measure and develop these further or that they feel little accountability and involvement other than 'having a goal' to share with their ATs and VLs. STs' reported reflective practices indicate they may not undertake 'productive' reflection (Bayat, 2010), raising questions about the relevance of STs' goals, reflection and the role of ITE programmes in assisting STs to develop these skills. These findings raise questions about how STs develop their agency and sense of efficacy when reflection and practicum goals are undertaken superficially and there is little apparent regard to ST accountability or strategies to measure and monitor progress.

\section{Relationships and assessment: transparency and agency}

STs in this study reported they were satisfied overall with how their ATs undertook their roles yet they were not always happy with their relationship and communication with their AT or the feedback and 
support received from them. Similarly, STs raised concerns about the apparent consistency and perceived transparency of their VLs' support, guidance and assessment. STs appear adrift in uneasy tides of their own agency and it may have been somewhat fortuitous when placements with ATs and VLs' assessments enabled increased ST understandings and development. These findings are similar to those reported by Aspden (2017).

STs' feelings of vulnerability within the practicum contexts they find themselves has been previously indicated by Aspden (2017) who found assessments were positive where AT-ST relationships were functioning well. Aspden (2017) argued it was more by good fortune than design and preparation that students found themselves in supportive responsive practicum contexts which matched their expectations. It would appear this study indicates similar findings. The role of the ECE teaching practicum administrator may be a key factor in this 'good fortune'. They are the ones who have regular contact over time with STs, ATs, VLs and centres and who match the fit of each to ST's needs. They are also the first contact and responder for each within this triad, often fielding issues before being passed to the programme director.

While collaboration and partnership are inherent within NZ ECE epistemology (see Ministry of Education, 1996; New Zealand Teachers Council, 2015; Education Council New Zealand, 2019) they may not always be evident in the enaction of practicum partnerships. Inherent within the hierarchical relationships evident in the practicum triad is the presence of hierarchical power relationships (Aspden, 2017), silence (Ortlipp, 2003) and vulnerability (Murphy \& Butcher, 2013). The tension for STs in this study appears to lie in their agency and sense of vulnerability in understanding assessment processes. In assessment, power may be perceived by STs as beyond their influence (Aspden, 2017; Murphy \& Butcher, 2013; Turnbull, 2005). In this study STs appeared to respond to the ECE climate, judging whether it was compatible with their beliefs and expectations of support and practices. This judgement in turn appeared to influence ST agency - whether they voiced their views, filtered feedback or tactically complied. This may be closely linked to their prior experiences and tacit beliefs about their roles as teachers within education as suggested by Biesta et al., (2015) and Sumsion (1998).

STs appeared to perceive the AT role as vital from the outset, measuring authenticity of welcome, inclusion and centre climate within teachers' congruence of word and deed or relational trust (see Bryk \& Schneider, 2003). The perceived climate of relational trust within centres appeared to enable or hinder ST agency, emotion, relationships and communication during practicum in this study. STs reported disappointment when ATs didn't make time for meetings, provide feedback or deliver written reports as agreed that may have influenced STs' relational trust and investment in practicum 
relationships. Murphy and Butcher (2013) found STs' perceptions of AT investment in STs' development was influenced by ATs' honouring of meeting agreements between them and their STs. Moles et al. (2012) and Murray (2015) suggest cultural expectations also influence expectations of AT feedback. A third of STs in this study reported AT feedback was not at all helpful, while overall STs were appreciative of ATs assistance. STs' perceptions of AT feedback and 'fit' in the current study indicate some ATs could be more attentive to STs in modelling practices, discussing STs' ideas and in their written feedback

Some STs reported VLs appeared inconsistent in their approach to assessment visits either not observing, not observing long enough or providing what STs' perceived as contradictory verbal and written VL feedback. Ortlipp $(2003,2009)$ found VLs juggled their roles within competing tensions of assessment, support, congeniality, development of STs' confidence and risk within challenging practices that could engender STs' or ATs' discomfort, while Aspden (2017) argued practicum assessment lay heavily within the subjectivities and professional judgements of VLs. These studies suggest a need for further discussion and transparency in practicum assessment processes. STs' perceptions in this study also raise questions about consistency of VL approaches to assessment visits, STS' understanding of, and agency within, the assessment process, as well as the manner in which VLS support STs' confidence while providing sensitively timed challenges to strengthen STs' reflective practices and development.

\section{Video Review}

The findings of this study indicate that STs were ambivalent about using VR, acknowledging both the anticipated and, for some, already experienced challenges of 'seeing' themselves. These results are mirrored in the findings of multiple studies where STs' initial preoccupation with their appearance, self-image and subsequent self-judgements limited their abilities to reflect beyond a superficial overview of the teaching context and their roles (e.g., Bower et al., 2011; La Paro et al., 2012; Navin, 2018). STs' primary concerns in this study seemed to be in their experienced or anticipated vulnerability to self-judgment and the additional stress they had experienced or anticipated in filming, seeing themselves at work with children and exploring their practices with ATs and VLs. The deprivatisation of STs' practices, their feelings of authenticity as they are filmed and confronting images of themselves were indicated as significant challenges of VR by STs while recognising what they do well in their teaching and developing strategies to strengthen their teaching appeared to be secondary concerns.

Students in this study reported that they recognised video review could be beneficial to their teaching development during practicum in numerous ways. Seeing their practice as others do, what they might 
improve and what they already do well were reported as potential benefits of VR by STs. Several STS acknowledged the benefits of VR in reconciling discrepancies between how they remembered events, and the written or verbal feedback received from ATs or VLs with the unbiased feedback offered by VR; a finding mirrored by numerous studies (Atiles \& Pinholster, 2013; Bayat, 2010; Bower et al., 2011; Coffey, 2014; Navin, 2018). STs' utilisation of VR to see, to self-identify and self-evaluate their teaching practices has been reported to increase STs' capacity to generate solutions and change in their practice (Bayat, 2010; Coffey, 2014; Joseph \& Brennan, 2013).

Numerous authors recognise the benefits of having a record of change and growth in ST practices (Joseph \& Brennan, 2013; Navin, 2018). Providing a means for STs to 'see' their practice, make decisions about changes in practice and record progress increased ST's sense of ownership and efficacy according to Bower et al. (2011). Students in this current study identified similar potential of VR to reference in their professional discussions with ATs and VLs. STs identified that, rather than relying on anecdotal notes and memories of STs' practices, VR might provide a common ground from which to discuss video events. Several STs suggested VR might be useful in arguing their own point of view during discussion, suggesting it may also strengthen STs' confidence and agency during practicum.

Utilising VR in professional discussions to explore perspectives was identified by STs as both potentially beneficial and problematic in this study. STs' comments suggesting the benefits of exploring perspectives in discussion was tied to seeing their practice, and reconciling beliefs about their practice with what was visible. The challenges of VR discussion reported by STs were also around the de-privitisation of their practice and the anticipated judgements of others. Possibly, STs interpreted potential 'VR use during practicum' as a replacement assessment tool within the traditional VL observation and discussion model rather than VR as a tool utilised throughout practicum for discussion, critical reflection and teacher development. While some STs in this study indicated they welcomed opportunities to explore practicum triad perspectives during discussion using VR, several studies have found VR analysis and discussion problematic without ST practice (Bower et al., 2011), structured guides (Baecher et al.,2013), and mentor prompts (Bayat, 2010). Utilisation of VR to discuss perspectives may be limited without agreed expectations and a climate that supports the generation of "productive disagreements" to examine beliefs, suggests Hatch et al., (2016, p.283). The importance of time for deliberation and reflection between AT/VL-ST discussions, was reported by Smith and Lev Ari (2005) and Hatch et al. (2016) as crucial for STs. VR and the 
distance afforded from teaching events may provide opportunities for increased ST agency (intrinsic motivation and responsibility) as well as time for triad members to examine subjectivities.

The potential of VR use throughout ITE programmes as well as practicum has been explored extensively internationally but appears absent within NZ literature. The results of this study in conjunction with the literature reviewed indicate that students' use of VR during practicum, if implemented sensitively, may afford STs' opportunities to increase their agency, feelings of confidence and enable increasingly equitable practicum support and assessment processes.

\section{Limitations of this study}

This study's data was limited by the survey format. Interviews of STs may have enabled further probing of STs' perceptions and experiences, providing more nuanced data, analysis and results. The STs surveyed were from one New Zealand ITE programme and as such the results are not transferrable or generalisable (Creswell \& Guetterman, 2019) to other ECE ITE programmes. There may also have been ST conscious or unconscious self-bias within survey responses. The length of surveys may have resulted in survey fatigue for those STs completing the complete post-practicum survey.

Difficulties with the survey design and administration were due to the inexperience of the researcher, including:

- Initial omission of 'forced response' questions in the pre-practicum survey which were remedied in the post-practicum survey.

- a question that should have had a multiple answer option discovered and activated early in the initial survey.

\section{Conclusion}

This study found student teachers perceive practicum as highly significant within their ITE. STs report they value practicum opportunities to develop ther knowledge and skills in the real-world context of ECE centres with children and within teaching teams. However, STs also report a wide range of perceived challenges, indicating that the practicum is problematic at times. These challenges involve the establishment of relationships and communication, transparency of assessment practices, and STs' agency. These issues impact upon ST responses within, and perceptions of, their practicum experience. Each of these threads appear inter-related. Sitting within these threads is the traditional NZ practicum model in which STs observe (Bandura, 2001) and practice teaching in ECE centres under the guidance of an AT and VLs to support, guide and assess STs' practice. Although there have been 
ongoing recommendations for further support and preparation of STs (Aspden, 2017), ATs (Murphy \& Butcher, 2013; Turnbull, 2005) and VLs (Ortlipp, 2003), the same issues appear to be surfacing for students in this research. This study also found student teachers, while ambivalent to the option of VR use during practicum, acknowledged the potential benefits to their teacher development and within assessment including seeing their practice as others do and reconciling memories of events with feedback. Given that agency, efficacy and motivation are malleable (Bandura, 2001; Dweck, 2000) these issues seem particularly relevant to ITE programmes. Ortlipp argues addressing inherent practicum assessment subjectivities may create spaces for participants to "think, speak and act differently" (2009, p.165). Addressing this space may invite and elucidate subjectivities providing both more and less choice and subsequent agency. Ortlipp also argues "to make choices about voice and silence that may produce different effects for those involved in practicum assessment" may assist each of the practicum triad (2003, p.236). Such effects might support feedback, exploration of assumptions and perspectives, creation of possible directions for development collaboratively as well as strengthening what STs report as challenging, 'recognising what I do well'. VR may provide a space within the traditional practicum model for such change.

\section{Implications}

The findings of this study provide further evidence of the need to re-examine the traditional practicum model and to consider alternative approaches by ITE's. The implications of this study for ITE programmes include further exploration of how such programmes might further foreground, investigate and strengthen: ST agency, tacit beliefs, reflective processes, development and monitoring of teaching goals; ST emotion as transformative cues; preparation of STs', ATs' and VLs' communication and assessment expectations within practicum relationships; re-examination of the traditional NZ practicum model; and potential of VR to strengthen ST development. 


\section{References}

Andres, L. (2012). Designing and doing survey research. London, England: Sage.

Aspden, K. M. (2017). The complexity of practicum assessment in teacher education: An examination of four New Zealand case studies. Australian Journal of Teacher Education, 42(12), 128-143.

Atiles, J., \& Pinholster, L. (2013). Student teaching: Reflections of a relentless journey. Journal of Early Childhood Teacher Education, 34(4), 308-319.

Baecher, L., Kung, S-C., Jewkes, A., \& Rosalia, C. (2013). The role of video for self-evaluation in early field experiences. Teaching and Teacher Education, 36, 189-197.

Bandura, A. (2001). Social cognitive theory: An agentic perspective. Annual Review of Psychology, 52, $1-26$.

Bayat, M. (2010). Use of dialogue journals and video-recording in early childhood teacher education. Journal of Early Childhood Teacher Education, 31(2), 159-172. doi:org/10.1080/10901021003781247

Biesta, M., Priestley, M., \& Robinson, S. (2015). The role of beliefs in teacher agency. Teachers and Teaching, 21(6), 624-640. doi:org/10.1080/13540602.2015.1044325

Bower, M., Cavanagh, M., Moloney, R., \& Dao, M. (2011). Developing communication competence using an online video reflection system: Pre-service teachers' experiences. Asia-Pacific Journal of Teacher Education, 39(4), 311-326.

Borko, H., \& Mayfeild, V. (1995). The roles of the cooperating teacher and the university supervisor in learning to teach. Teaching and Teaching Education, 11(5), 501-518.

Braun, V., \& Clarke, V. (2006). Using thematic analysis in psychology. Qualitative Research in Psychology, 3, 77-101. doi:10.1191/1478088706qp063oa

Bryk, A., \& Schneider, B. (2003). Trust in schools. Educational Leadership, 60(6), 40-44.

Bullock, A., Coplan, R., \& Bosacki, S. (2015). Exploring links between early childhood educators' psychological characteristics and classroom management self-efficacy beliefs. Canadian Journal of Behavioural Science, 47(2), 175-183. doi:org/10.1037/a0038547

Caires, S., Almeida, L., \& Vieira, D. (2012). Becoming a teacher: Student teachers' experiences and perceptions about teaching practice. European Journal of Teacher Education, 35(2), 163-178. doi:org/10.1080/02619768.2011.643395 
Coffey, A. M. (2014). Using video to develop skills in reflection in teacher education students. Australian Journal of Teacher Education, 39(9), 86-97. doi:org/10.14221/ajte.2014v39n9.7

Creswell, J \& Guetterman, T. (2019). Educational research: Planning, conducting and evaluating quantitative and qualitative research ( $6^{\text {th }}$ ed.). New York, NY: Pearson.

Dweck, C. (2000). Self-theories: Their role in motivation, personality, and development. New York, NY: Taylor \& Francis.

Dweck, C., \& Leggett, E. (1988). A social-cognitive approach to motivation and personality. Psychological Review, 95(2), 256-273.

Education Council New Zealand. (2019). Code of professional responsibility and standards for the teaching profession. Wellington, New Zealand: NZEC.

Fives, H., Hamman, D., \& Olivarez. (2007). Does burnout begin with student-teaching? Analyzing efficacy, burnout and support during the student-teaching semester. Teaching and Teacher Education, 23, 916-934.

Gibbons, A., Tesar, M., Steiner, S., \& Chan, S. (2018). Silent policymakers in Aotearoa New Zealand: Reflections on research of early childhood teacher views on policy, practicum and partnership. Open Review of Educational Research, 5(1), 43-55. doi:org/10.1080/23265507.2018.1461025

Goddard, R., Hoy, W., \& Woolfolk Hoy, A. (2000). Collective teacher efficacy: Its meaning, measure and impact on student achievement. American Educational Research Journal, 37(2), 479-507.

Goleman, D. (1996). Emotional Intelligence: Why it can matter more than IQ. London: Bloomsbury.

Haigh, M., \& Ward, G. (2004). Problematising practicum relationships: Questioning the 'taken for granted'. Australian Journal of Education, 48(2), 134-148.

Hatch, T. Shuttleworth, J., Jaffee, A., \& Marri, A. (2016). Videos, pairs, and peers: What connects theory and practice in teacher education? Teaching and Teacher Education, 59, 274-284.

Holland, J. (2007). Emotions and research. International Journal of Social Research Methodology, 10(3), 195-209.

Joseph, G., \& Brennan, C. (2013). Framing quality: Annotated video-based portfolios of classroom practice by pre-service teachers. Early Childhood Education Journal, 41(6), 423-430.

Johnson, B., \& Christensen, L. (2014). Educational research: Quantitative, qualitative, and mixed approaches ( $5^{\text {th }}$ ed.). Thousand Oaks, CA: Sage. 
La Paro, K., Maynard, C., Thomason, A., \& Scott-Little, C. (2012). Developing teachers' classroom interactions: A description of a video review process for early childhood education students. Journal of Early Childhood Teacher Education, 33(3), 224-238.

La Paro, K., Van Schagen, A., King, E., \& Lippard, C. (2018). A systems perspective on practicum experiences in early childhood teacher experience: Focus on interprofessional relationships. Early Childhood Education Journal, 46, 365-375.

Loizou, E. (2011). The diverse facets of power in early childhood mentor-student teacher relationships. European Journal of Teacher Education, 34(4), 373-386.

Madrid, S., Baldwin, N., \& Frye, E. (2013). "Professional feeling": One early childhood educator's emotional discomfort as a teacher and learner. Journal of Early Childhood Research, 11(3), 274291.

Merriam, S., \& Tisdell, E. (2016). Qualitative Research: A guide to design and implementation ( $4^{\text {th }}$ ed.). San Francisco, CA: Jossey-Bass. Retrieved from http://search.ebscohost.com.helicon.vuw.ac.nz/login.aspx?direct=true\&db=nlebk\&AN=1022562 \&site=ehost-live

Ministry of Education. (1996). Te Whāriki. He whāriki matauranga mō ngā mokopuna o Aotearoa: Early childhood curriculum. Wellington: Learning Media.

Moles, J., Tanielu-Dick, B., Atiga-Anderson, V., Sauvao, L., Fuimaono, H., Ryan, S., de Rose, S., Ferguson, J., Fuli-Makaua, L., \& Brown, V. (2012). (Re) Viewing the landscape inside and outside the box: Providing effective support for early childhood student teachers. New Zealand Research in Early Childhood Education, 15, 145-159.

Murphy, C., \& Butcher, J. (2013). "They took an interest": Student teachers' perceptions of mentoring relationships in field-based early childhood teacher education. New Zealand Research in Early Childhood Education, 16, 45-61.

Murray, S. (2015). Equitable teaching practicum: A key to success for immigrant Asian early childhood student teachers and their associates? He Kupu, 4(2), 16-28.

Navin, L. (2018). Does seeing matter? Exploring pre-service teachers' use of self-video as a tool for selfreflection in the study of their own practice. Published PhD thesis. University of Missouri-St Louis. 
New Zealand Teachers Council. (2015). Graduating teacher standards: Aotearoa, New Zealand. Wellington, New Zealand: NZTC.

New Zealand Teachers Council. (2019). Initial teacher education programme approval, monitoring and review requirements. Wellington, New Zealand: NZTC.

Ord, K., \& Nuttal, J. (2016). Bodies of knowledge: The concept of embodiment as an alternative to theory/practice debates in the preparation of teachers. Teaching and Teacher Education, 60, 355-362.

Ortlipp, M. (2003). The risk of voice in practicum assessment. Asia-Pacific Journal of Teacher Education, 31(3), 225-237. doi:org/10.1080/095523603200014936

Ortlipp, M. (2009). Shaping conduct and bridling passions: Governing practicum supervisors' practice of assessment. Contemporary Issues in Early Childhood, 10(2), 156-167.

Osgood, J. (2010). Reconstructing professionalism in ECEC: The case for the 'critically reflective emotional professional'. Early Years, 30(2), 119-133.

Smith, K., \& Lev-Ari, L. (2005). The place of the practicum in pre-service teacher education: The voice of the students. Asia-Pacific Journal of Teacher Education, 33(3), 289-302.

Smith, K. (2016). Partnerships in teacher education - going beyond the rhetoric, with reference to the Norwegian context. Center for Educational Policy Studies Journal, 6(3), 17-36.

Stephenson, A. (2006). Troubling teaching. Australian Journal of Early Childhood, 31(1), 51-55.

Sumsion, J. (1998). Stories from discontinuing student teachers. Teachers and Teaching, 4(2), 245258.

Sumsion, J. (2000). Facilitating reflection: A cautionary account. Reflective Practice, 1(2), 199-214.

Tschannen-Moran, M., \& Woolfolk Hoy, A. (2001). Teacher efficacy: Capturing an elusive construct. Teaching and Teacher Education, 17, 783-805.

Turnbull, M. (2005). Student teacher professional agency in the practicum. Asia Pacific Journal of Teacher Education, 33(2), 195-208.

Turnbull, M. (2007). The early childhood practicum as a social system. New Zealand Research in Early Childhood Education, 10, 169-181. 
Van Schagen Johnson, A., La Paro, K., \& Crosby, D. (2017). Early childhood experiences: Pre-service early childhood students' perceptions and sense of efficacy. Early Childhood Education Journal, 45, 229-236.

Zhang, Q., Cown, P., Hayes, J., Werry, S., Barnes, R., France, L., \& TeHau-Grant, R. (2015). Scrutinising the final judging role in assessment of practicum in early childhood initial teacher education in New Zealand. Australian Journal of Teacher Education, 40(10).

doi.org/10.14221/ajte.2015v40n10.9 
Appendix A.

\section{New Zealand (NZ) Early Childhood Education (ECE) preservice teachers' perceptions of practicum and potential video review. RECRUITMENT INVITATION AND PARTICIPANT INFORMATION EMAIL}

Please read this information before deciding whether or not to take part. If you decide to participate, thank you. If you decide not to participate, thank you for considering this request.

\section{Who am I?}

My name is Susie Bassett and I am a Master's student in Education at (removed for confidentiality). This research project is work towards my Master's thesis.

\section{What is the aim of the project?}

This project aims to understand the experiences of Early Childhood Education (ECE) student teachers on their practicum, and student teacher thoughts about the value of video review (perceived or experienced) of their own teaching.

My research design involves student teachers completing one to two anonymous on-line surveys, one before the practicum and another at the completion of the practicum. Student teachers can choose to do either survey or both surveys.

This research has been approved by the (removed for confidentiality) Human Ethics Committee (reference application number \#0000026822).

\section{How can you help?}

You have been invited to participate because you are a student teacher at (removed for confidentiality) undertaking a Bachelor of Education (Teaching) Early Childhood. If you wish to take part, you can complete an anonymous on-line survey before the $15^{\text {th }}$ October and / or complete another anonymous online survey at the end of the practicum (between the $23^{\text {rd }}$ November and 7th December). This will contribute to data gathered for the purposes of this study.

Participation is voluntary and the data you provide as part of the research project will be anonymous.

If you have any concerns about the ethical conduct of the research, you may contact the (removed for confidentiality) Human Ethics Committee Convener: (removed)

Each survey is estimated to take 10-20 minutes to complete. By accessing the survey, you consent to participate. 
You can withdraw from the study before you submit any survey you view or partially complete by not clicking on the 'submit survey' option.

Each combined group of respondents completing the Pre Practicum survey and/or the Post Practicum survey can volunteer to enter a draw for either $\$ 100$ book voucher or $\$ 100$ grocery voucher of their choosing (total 2 draws). This gift is provided as an acknowledgment of your contributions to this project. If you wish to enter this draw a link will direct you to an additional site where you may provide your email address. This is to ensure your anonymity and will not be able to be linked to your survey data. Winners of each draw will be notified by email (late October and December).

\section{What will happen to the information you give?}

This research is anonymous. This means that I (the researcher named below) will not be aware of your identity.

All data will be kept securely by the researcher in password protected files and/or as hard copies in locked filing cabinets. These will be destroyed 31/1/2022.

\section{What will the project produce?}

The information from my research will be used in my Master's thesis and in possible academic and professional publications and conferences. Little research into initial teaching experience and/or practicum has been undertaken particularly in the New Zealand context. This project may help inform further programme design and review both at (removed for confidentiality) and in other New Zealand Initial teacher education programmes.

\section{If you accept this invitation, what are your rights as a research participant?}

You do not have to accept this invitation if you don't want to. If you do decide to participate, you have the right to:

- $\quad$ withdraw from the project;

- $\quad$ ask any questions about the study at any time;

- $\quad$ read over a summary of the survey data (on request);

- $\quad$ be able to read any reports of this research by emailing the researcher to request a copy.

\section{To access the survey, please click on this link:}

\section{If you have any questions or problems, who can you contact?}

If you have any questions about this project, either now or in the future, please feel free to contact: Susie Bassett or Sue Cherrington (details removed)

On completion of any survey, if you wish to discuss your practicum experiences further please contact:

(Removed for confidentiality) 
Appendix B.

\section{Post Practicum Survey}

\section{Start of Block: Default Question Block}

Did you complete the Pre-Practicum survey?

Yes

No

\section{Skip To: End of Block If Did you complete the Pre-Practicum survey? = Yes}

Are you in:

Year 2 of the BEd(Tchg)EC degree?

Year 3 of the BEd(Tchg)EC degree

Other (please elaborate)

Are you:

Male

Female

Trans

Other

Would rather not say 
Are you aged?

Under 20 years

21- 30 years

31- 40 years

41 - 50 years

51 - 60 years

Over 60 years

Which ethnic groups do you identify with (please select all that apply)?

Pakeha New Zealander

European

New Zealand Maori

Asian

Pasifika

Other and/or combination (please specify)

How many practicums have you completed so far in your degree?

One

Two

Three

Four

Five 
Please indicate how significant each of the following aspects are in your development as an early childhood teacher.

\begin{tabular}{c|c} 
Going on practicum \\
$\begin{array}{c}\text { Gaining experience } \\
\text { working with young } \\
\text { children }\end{array}$ \\
$\begin{array}{c}\text { Gaining experience } \\
\text { of working in a } \\
\text { team of ECE } \\
\text { teachers }\end{array}$ \\
$\begin{array}{c}\text { Putting the theory } \\
\text { learned in my }\end{array}$ \\
university classes \\
into practice \\
Reflecting on my \\
practice as a \\
student teacher \\
Opportunities to \\
develop confidence \\
Opportunities to \\
manage challenges \\
constructively \\
Opportunities to \\
discuss my \\
teaching practices \\
in context \\
Get feedback on \\
my teaching \\
practices
\end{tabular}

Thinking about your responses to the last question, what are the most important aspects of the practicum in relation to your own learning as a developing teacher? 
When you were on practicum, did you (select all that apply):

Identify professional goals for my own teaching development (eg.curriculum, workload, relationships)

$\square$ Identify personal goals for myself (eg. personal competence, performance, confidence)

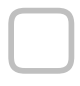

Have some general ideas about what I would like to achieve but don't frame these as goals

Share my goals/ideas with my Associate Teacher

Share my goals/ideas with other teachers in the centre

Share my goals/ideas with my Visiting Lecturer(s)

Include learning derived from my own goals/ideas in my practicum assignments 
To what extent do you:

All the time Hardly ever
$\begin{aligned} & \text { Develop strategies } \\ & \text { to help me achieve } \\ & \text { my goals/ideas } \\ & \text { Reflect on my } \\ & \text { progress in } \\ & \text { achieving my goals/ } \\ & \text { ideas } \\ & \text { Re-visit my } \\ & \text { goals/ideas to see } \\ & \text { if they are still } \\ & \text { relevant } \\ & \text { Build on the goals I } \\ & \text { set for one } \\ & \text { practicum in my } \\ & \text { next practicum } \\ & \text { Find my goals/ideas } \\ & \text { remain the same } \\ & \text { from one } \\ & \text { practicum to the } \\ & \text { next }\end{aligned}$

Thinking about this last practicum, what were you most concerned with developing?

How challenging did you find the following on this practicum? 
Managing my workload and time

Managing children's behaviours and wellbeing

Managing my own wellbeing (e.g., my energy, stress levels, confidence and feelings of competence)

Managing the relationship with my Associate Teacher

Managing the relationship with the other teachers in the team

Building relationships with children

Building relationships with parents and whanau

Completing the practicum assignments

Writing assessments of children's learning

Using assessments of children's learning to plan learning experiences

Being able to reflect on my practices

Being able to select and use different teaching strategies with children

Creating and facilitating relevant learning experiences with children

Working on the aspects of my practice I want to develop 
Visiting Lecturer

assessments

(observation, discussion,

report)

With the above responses in mind, what did you find most challenging? (Please describe). 
On this practicum, how often did you feel: (Please provide the first example that comes to mind for each emotion in each text box)

\begin{tabular}{|c|c|c|c|c|}
\hline & Most of the time & Often & Rarely & Never \\
\hline $\begin{array}{l}\text { Energised and } \\
\text { happy (when...) }\end{array}$ & $\bigcirc$ & & & \\
\hline $\begin{array}{l}\text { Relaxed / at ease } \\
\text { (because...) }\end{array}$ & $\bigcirc$ & & & \\
\hline Confident (when...) & & & & \\
\hline $\begin{array}{c}\text { Anxious } \\
\text { (because...) }\end{array}$ & & & & \\
\hline Frustrated (when...) & 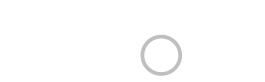 & & & \\
\hline $\begin{array}{l}\text { Satisfied } \\
\text { (because...) }\end{array}$ & C & & & \\
\hline $\begin{array}{l}\text { Supported/ able to } \\
\text { choose the } \\
\text { direction of your } \\
\text { development } \\
\text { (when...) }\end{array}$ & & & & \\
\hline $\begin{array}{l}\text { Respected } \\
\text { (because...) }\end{array}$ & 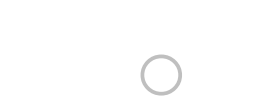 & & & \\
\hline Cautious (when...) & & & & \\
\hline Other & & & & \\
\hline
\end{tabular}

What do you feel had the biggest impact on these feelings during this practicum? (eg. personal situation, work, study, professional philosophy, support) 
How helpful was your Associate Teacher in your teaching development this practicum?

\begin{tabular}{c|c}
$\begin{array}{c}\text { Discussion of my ideas } \\
\text { and observations } \\
\text { Offered advice and } \\
\text { guidance that developed } \\
\text { my teaching }\end{array}$ \\
Written reports \\
Encouragement \\
Acknowledgment and \\
support \\
Included me in all aspects \\
of the teaching team \\
$\begin{array}{c}\text { Modeling of } \\
\text { inspiring/achievable } \\
\text { practices }\end{array}$ \\
Other (please describe)
\end{tabular}

Thinking about the responses above, is there anything you want to add? 
Please click on any statements which you agree with:

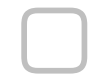

I received Associate feedback frequently

I received Associate feedback as I worked (gesture, facial expression, comments, conversation)

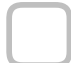

I received Associate feedback during breaks

I received Associate feedback in formal meetings

I felt my Associate's feedback assisted my learning

I felt my Associate's feedback hindered my learning

Other members of the teaching team gave me useful feedback

I preferred feedback from other members of the teaching team

I felt my Associate's feedback included other teachers' views of my work

I felt my Associate's feedback was fair and constructive

Thinking about your responses above, is there anything you want to comment on? 
Please click on any statements which you agree with:

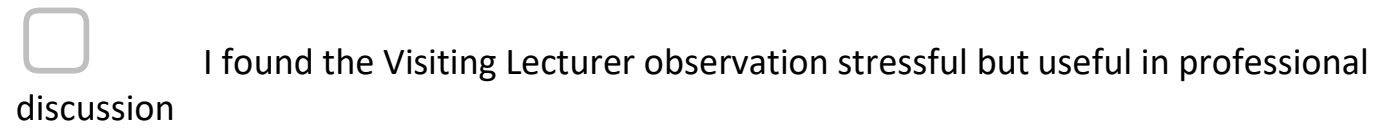
discussion

I don't say much during the Visiting Lecturer discussion, I'm there to listen to the Visiting Lecturer's views

The Visiting Lecturer professional discussion felt like a test

I found the Visiting Lecturer discussion useful for next steps/strategies to develop my practices

I was confused by the Visiting Lecturer's feedback in the professional discussion

I found the Visiting Lecturer report summarised what was observed and discussed

I was able to contribute to my Visiting Lecturer's assessment by discussing my teaching decisions and approach to teaching

I get through the Visiting Lecturer assessment visit, then forget about it

Thinking about the Visiting Lecturer assessment (observation, discussion, report) process, is there anything you would like to add? (please describe)

I am interested in your ideas about the use of video to reflect on your own practice on practicum. Have you used video review of your own teaching during your training?

Yes

No 
How challenging were the following?/ How challenging would you anticipate the following?

\begin{tabular}{l|l} 
Seeing/hearing myself & Very challenging \\
Being filmed/being my \\
'usual' teaching self \\
Sharing my video with \\
others \\
Gaining consent \\
Planning for filming \\
Reflecting on my \\
teaching practices \\
Recognising what I did \\
well
\end{tabular}


To what degree do you agree with the following:

\begin{tabular}{l|l|} 
& Absolutely agree $\quad$ Somewhat agree Don't agree at all Not applicable \\
\hline $\begin{array}{c}\text { Video review helps } \\
\text { me to see my } \\
\text { practices as others } \\
\text { see them }\end{array}$ \\
Video review was \\
disconcerting but I \\
got used to it \\
Video review is \\
something that I \\
want to continue \\
because I see its \\
value in my \\
teaching \\
development \\
Video review is \\
something that I \\
want to avoid \\
Video review \\
would be useful in \\
my discussions \\
with my Associate \\
and/or the Visiting \\
Lecturer \\
Video review is \\
best left for me to \\
reflect upon alone
\end{tabular}

Would you voluntarily use video review of your own teaching while on practicum? (briefly elaborate)

Yes, because

Maybe, because

No, because

Do you feel that video review might have assisted your discussions with your Associate and Visiting Lecturer? (Please elaborate) 
Thank you for participating. If you would like to go into the draw for a $\$ 100$ book or grocery voucher, please click on this link to provide your email address. (Your email address can not be linked to the data you have provided) http://vuw.qualtrics.com/jfe/form/SV_bC8PV4MdEBfRcyx

\section{End of Block: Default Question Block}

\section{Start of Block: Block 2}

How helpful was your Associate Teacher in your teaching development this practicum?

\begin{tabular}{c|c|} 
& Extremely helpful \\
\hline $\begin{array}{c}\text { Discussion of my ideas } \\
\text { and observations } \\
\text { Offered advice and } \\
\text { guidance that developed } \\
\text { my teaching }\end{array}$ \\
Written reports \\
Encouragement \\
Acknowledgment and \\
support \\
Included me in all aspects \\
of the teaching team \\
$\begin{array}{c}\text { Modeling of } \\
\text { inspiring/achievable } \\
\text { practices }\end{array}$ \\
Other (please describe)
\end{tabular}


To what degree do you agree with the following:

\begin{tabular}{l|l} 
I felt respect and regard \\
with my Associate \\
I was given responsibility \\
and trusted in my \\
student teacher roles \\
We had similar ideas \\
about teaching style, \\
best practice and guiding \\
children's behaviour \\
I felt my Associate \\
showed a personal \\
interest in me as well as \\
my teaching \\
I was responsive in my \\
communications with my \\
Associate \\
My Associate shared \\
information about the \\
Centre's beliefs, practices \\
etc with me
\end{tabular}

Thinking about the responses above, is there anything you want to add? 
Please click on any statements you agree with:

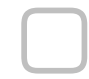

I received Associate feedback frequently

I received Associate feedback as I worked (gesture, facial expression, comments, conversation)

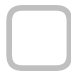

I received Associate feedback during breaks

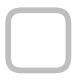

I received Associate feedback in formal meetings

I felt my Associate's feedback assisted my learning

I felt my Associate's feedback hindered my learning

I preferred feedback from other members of the teaching team

I felt my Associate's feedback included other teachers' views of my work

I felt my Associate's feedback was fair and constructive

Thinking about your responses above, is there anything you want to comment on? 
Please click on any statements which you agree with:

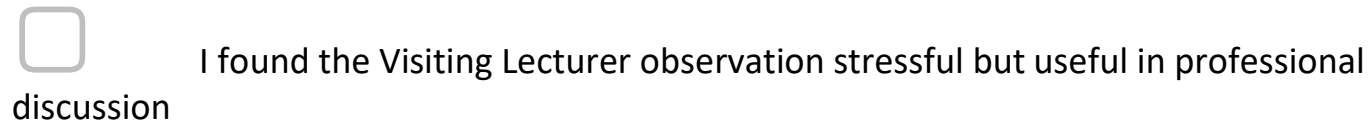
discussion

I don't say much during the Visiting Lecturer discussion, I'm there to listen to the Visiting Lecturer's views

The Visiting Lecturer professional discussion felt like a test

I found the Visiting Lecturer discussion useful for next steps/strategies to develop my practices

I was confused by the Visiting Lecturer's feedback in the professional discussion

I found the Visiting Lecturer report summarised what was observed and discussed

I was able to contribute to my Visiting Lecturer's assessment by discussing my teaching decisions and approach to teaching

I get through the Visiting Lecturer assessment visit then forget about it

Thinking about the Visiting Lecturer assessment (observation, discussion, report) process, is there anything you would like to add? (please describe)

Do you feel that video review might have assisted your discussions with your Associate and Visiting Lecturer? (Whether yes or no, Please elaborate) 
Thank you for participating. If you would like to go into the draw for a $\$ 100$ book or grocery voucher, please click on this link to provide your email address. (Your email address can not be linked to the data you have provided).

http://vuw.qualtrics.com/jfe/form/SV_bC8PV4MdEBfRcyx 